\title{
Subjective Interest Rate Uncertainty and the Macroeconomy: A cross-country analysis
}

\author{
Klodiana Istrefi ${ }^{1}$, Sarah Mouabbi ${ }^{2}$ \\ Working Paper \#619 \\ January 2017
}

\section{ABSTRACT}

We ask whether uncertainty about interest rates is important for economic activity. Effects of interest rate uncertainty on the economy are examined through the lens of a small VAR where the assumption that uncertainty can affect real activity contemporaneously but not vice versa is indeed in line with the data. Our measure of uncertainty stems from professional forecasts of short- and long-term interest rates and accounts for both disagreement among forecasters and the perceived variability of future aggregate shocks. Studying a panel of countries we find that subjective interest rate uncertainty has large, negative and persistent effects on the economy.

Keywords: interest rates, subjective uncertainty, surveys of professional forecasters, macroeconomic fluctuations, structural VAR.

JEL classification : C32, E43, E47, F44, F47.

\footnotetext{
${ }^{1}$ Banque de France, Klodiana.Istrefi@banque-france.fr

${ }^{2}$ Banque de France, Sarah.Mouabbi@banque-france.fr

Working Papers reflect the opinions of the authors and do not necessarily express the views of the Banque de France. This document is available on the Banque de France Website.

Les Documents de travail reflètent les idées personnelles de leurs auteurs et n'expriment pas nécessairement la position de la Banque de France. Ce document est disponible sur le site internet de la Banque de France.
} 


\section{NON-TECHNICAL SUMMARY ${ }^{3}$}

This paper provides empirical evidence on the economic effects of subjective interest rate uncertainty, for several developed countries. Interest rate uncertainty as perceived by market participants is a major concern for central banks. Recent evidence of this is provided by the tapering episode in the US or the sell-off episode in the euro area in late April 2015, despite unchanged quantitative easing implementation details. In each case, interest rate uncertainty perceived by market participants led central banks to refine their language in an attempt to manage expectations. How can one measure such type of uncertainty? In this paper, interest rate uncertainty is based on forecasts of short- and long-term interest rates, 3 months ahead, stemming from Consensus Economics' surveys. Our measures account for two components, disagreement among forecasters and the perceived variability of future aggregate shocks. We have built these measures for the US, Japan, the UK, Canada, Sweden and four euro area countries: Germany, France, Italy, and Spain.

We estimate causal effects of subjective interest rate uncertainty on the economy through structural VARs, where the timing of Consensus Economics' surveys is exploited at the identification stage. Our subjective measure of uncertainty is constructed based on an information set that does not contain contemporaneous realizations of macro variables, thus warranting a recursive identification scheme where uncertainty can affect real activity contemporaneously but not vice versa. The multi-country dimension of our approach allows us to study if there is heterogeneity on the effects of uncertainty across different economies and if so, why? In this regard, information on economic structures and institutional frameworks is exploited for further insights.

Focusing on the last two decades, we find that interest rate uncertainty measures fluctuate substantially. For most countries, short-term interest rate uncertainty spikes during the recent financial crisis. Nonetheless, we observe substantial individual variation throughout the sample related to other important domestic events, on both the short- and the long-yield uncertainty. With regard to uncertainty on long-term yield, this measure appears to be noisy, except for Italy and Spain. These countries have been strongly affected during the 2011-2013 European sovereign debt crisis and the pressure exerted on their long-term yields is reflected in their corresponding uncertainties which reach their highest peak during that period. We also observe that for many countries, interest rate uncertainty is at the lowest levels, since the reach of the zero lower bound and the introduction of forward guidance communication on the policy rate from respective central banks.

Looking through the lens of country-specific VARs, we find that shocks to interest rate uncertainty have large and persistent negative effects on industrial production and unemployment. Furthermore,

\footnotetext{
${ }^{3}$ We thank Philippe Andrade, Nick Bloom, Regis Breton, Giovanni Caggiano, Olesya Grishchenko, Paul Hubert, Alejandro Justiniano, Lutz Kilian, Nobuhiro Kiyotaki, Julien Matheron, Barbara Rossi, Tatevik Sekhposyan, Leif Anders Thorsrud and participants in the Banque de France-Norges Bank Workshop in Empirical Macroeconomics, Banque de France-UCL 2nd Workshop on Uncertainty, 9th ECB Workshop on Forecasting Techniques, IAAE 2016 Annual Conference, 22nd International Conference on Computing in Economics and Finance, 3rd Joint Macro Workshop Banque de France -Bundesbank, Melbourne Institute Macroeconomic Policy Meetings, 2016 MBF Rome and OFCE Workshop in Empirical Monetary Economics for valuable suggestions. We thank Brigitte Arnaudo, Beatrice Saes-Escorbiac and Aurelie Tollet for their excellent research assistance.
} 
these shocks are deflationary. These results are in line with predictions from theoretical models studying macroeconomic effects of uncertainty. In terms of quantitative effects, there is substantial heterogeneity across countries, with the drop in production varying from 0.4 to 3.8 percent, within the year the shock hits. In response to this uncertainty, unemployment worsens with rates increasing by 0.15 to 1.2 percentage points. In addition, prices fall in response to interest rate uncertainty shocks, with producer prices falling up to 2 percentage points. Furthermore, the recovery of the economy to its initial levels is slow, taking about 3 to 5 years. When the two components of interest rate uncertainty measure are studied separately, we find that both shocks push the economy on the same adverse direction. Variations across the two components mainly appear on the magnitude and persistence of responses. All economies deteriorate immediately and rebound fast in response to disagreement shocks. In contrast, in response to common uncertainty, the economy slows down sluggishly but the troughs are on average larger and recoveries take longer.

When looking at the importance of these shocks, we find that short-yield uncertainty explains a large fraction of the variation in industrial production and unemployment. Emphasizing cross-country results, short-yield uncertainty explains between 42 to 59 percent of the variation in industrial production in Germany, France and Spain. Regarding unemployment, the contribution is substantial for the US (up to 40 percent) and Spain (up to 43 percent). Japan and Italy are two examples where such shocks do not seem important. Long-yield uncertainty explains relatively large variations of industrial production and unemployment for the US and Canada but not for the other countries.

Overall, this paper contributes to the literature of macroeconomic effects of uncertainty providing measures on subjective interest rate uncertainty for several countries and by studying their casual effect on the economy with credible assumptions for identification, supported by the timing of the surveys. We show that interest rate uncertainty has large negative effects on the economy, and those can be more adverse in some countries than others. In attempt to explain cross-country differences of interest rate uncertainty, we observe that effects are higher in countries with a larger share of interest-rate sensitive sectors and more labor market rigidities. This result suggests the importance of economic structures and institutional frameworks in propagating uncertainty shocks. Moreover, these findings draw attention to the role of central banks. They can design strategies to enhance transparency and communication, and mitigate interest rate uncertainty.. 


\section{RÉSUMÉ : INCERTITUDE SUBJECTIVE DES TAUX D'INTÉRÊT ET LA MACROÉCONOMIE}

Est-ce que l'incertitude sur les taux d'intérêt est importante pour l'activité économique? Les effets économiques de l'incertitude des taux d'intérêt sont examinés à travers un VAR où l'hypothèse que l'incertitude peut affecter instantanément l'activité réelle, mais pas vice versa, est en effet en accord avec les données. Notre mesure de l'incertitude provient de prévisions professionnelles des taux d'intérêt à court et à long terme et représente à la fois le désaccord entre les prévisionnistes et la variabilité perçue des chocs globaux futurs. Étudiant un groupe de pays, nous constatons que l'incertitude subjective des taux d'intérêt a des effets importants, négatifs et persistants sur l'économie.

Mots-clés : taux d'intérêt, incertitude subjective, enquêtes de prévisionnistes professionnels, fluctuations macroéconomiques, VAR structurel. 


\section{Introduction}

Interest rate uncertainty is a major concern for central banks. Recent evidence of this is provided by the tapering episode in the US or the sell-off episode in the euro area in late April 2015, despite unchanged quantitative easing implementation details. In each case, interest rate uncertainty perceived by market participants led central banks to refine their language in an attempt to manage expectations. From a macroeconomic point of view, there are at least three reasons why concerns about interest rate uncertainty are warranted. First, it might reflect uncertainty about monetary policy itself (see Creal and Wu, 2016; Istrefi and Piloiu, 2014; Baker et al., 2016). Second, at least at maturities beyond the direct control of central banks, it relates to financial uncertainty. As emphasized by Ludvigson et al. (2015), the latter is particularly important for business cycle fluctuations. Third, with a Taylor rule specification in mind, interest rate uncertainty might reflect uncertainty about the systematic component of monetary policy, hence about fundamentals (see Orphanides, 2000).

This paper contributes to the empirical literature on uncertainty, emphasizing the economic effects of interest rate uncertainty. ${ }^{1}$ To this aim, we make three distinct contributions. First, we build measures of interest rate uncertainty based on forecasts of short- and long-term interest rates, 3 months ahead, stemming from Consensus Economics' surveys (CE). Our measures account for two components, disagreement among forecasters and the perceived variability of future aggregate shocks, in line with Lahiri and Sheng (2010), thus representing a subjective interest rate uncertainty. In contrast to Lahiri and Sheng (2010), we enhance the estimation of the second component by using a stochastic volatility model rather than a GARCH-type model. This allows us to accommodate for the time-varying and stochastic nature we want the perceived variability of future aggregate shocks to feature.

The second contribution relates with the identification of subjective interest rate uncertainty shocks. Our approach relies on assumptions for identification that are supported by the temporal ordering of the data used in the analysis. More specifically, effects of interest rate uncertainty are measured by resorting to a structural VAR, where the timing of surveys is exploited at the identification stage. CE surveys are available on a monthly frequency, and forecasts are made generally within the first 10 days of the month. During this period, contemporaneous monthly data on economic activity are not known. Typically, the first indicators on industrial production, prices and employment situation for a particular month only start to become available during the second part of the month. Therefore, by construction, the CE forecasters' information set includes only past realizations of macroeconomic data when surveys are filled out. Thus, the temporal ordering of the data justifies a recursive identification scheme where uncertainty can affect real activity contemporaneously but not vice versa. Our identification strategy is similar in spirit to that of Leduc and Liu (2016) which also relies on the timing advantage of Michigan

\footnotetext{
${ }^{1}$ The empirical literature on uncertainty includes, among others, Mumtaz and Zanetti (2013), Fernandez-Villaverde et al. (2015), Jurado et al. (2015), Ludvigson et al. (2015), Baker et al. (2016) and Leduc and Liu (2016).
} 
survey data relative to the timing of macroeconomic data releases to identify the effects of consumer uncertainty shocks on the macroeconomy.

Third, we provide a multi-country dimension, by estimating the effects of interest rate uncertainty on a number of countries characterized by different economic structures and monetary policies. Our selected countries include the US, Japan, the UK, Canada, Sweden and four euro area countries: Germany, France, Italy, and Spain. The euro area group is particularity interesting as it shares a common monetary policy, and we measure uncertainty on the same short-term interest rate (i.e., the interbank rate) as perceived in these countries. Under our multi-country setup one can study if there is heterogeneity on the effects of uncertainty across different economies and if so, why? In this regard, we will exploit information on economic structures and institutional frameworks.

Focusing on the last two decades (when data availability allows), we find that interest rate uncertainty fluctuates substantially. Unsurprisingly, this measure spikes during the recent financial crisis for most countries, predominantly on short-term yield uncertainty. ${ }^{2}$ Nonetheless, we observe substantial individual variation throughout the sample related to other important domestic events. Around these events, interest rate uncertainty increases considerably, often exhibiting the highest magnitudes in our sample. We find that shocks to interest rate uncertainty have large and persistent negative effects on industrial production and unemployment. Furthermore, these shocks are deflationary. There is substantial heterogeneity across countries, with the drop in production varying from 0.4 to 3.8 percent, within the year the shock hits. In response to this uncertainty, unemployment worsens with rates increasing by 0.15 to 1.2 percentage points. In addition, prices fall in response to interest rate uncertainty shocks, with producer prices falling up to 2 percentage points. Furthermore, the recovery of the economy to its initial levels is slow, taking about 3 to 5 years.

Short-yield uncertainty is found to explain a large fraction of the variation in industrial production and unemployment. Results are the strongest for Spain where the share of the variation explained reaches up to 60 percent and 43 percent, respectively. Considering uncertainty on short versus long yields, the differences on the dynamic effects mostly appear on the quantitative side. Our findings suggest that subjective short-yield uncertainty is more important for the economy. When looking at disaggregated components of uncertainty, we find that both disagreement and the perceived variability of shocks push the economy in the same direction.

Overall, our paper shows that interest rate uncertainty has large negative effects on the economy, and those can be more adverse in some countries than others. A look into data patterns suggests that effects of interest rate uncertainty are higher in countries with a larger share of interest-rate sensitive sectors and more labor market rigidities. This result highlights the importance of economic structures and institutional frameworks in propagating uncertainty shocks. Moreover, these findings draw attention to the role of central banks. To the extent that interest rate uncertainty relates to uncertainty about monetary policy, central banks can design operational frameworks and strategies to mitigate them (see Ehrmann et al., 2012; Bianchi and Melosi, 2016). To the extent that interest rate uncertainty stems from

\footnotetext{
${ }^{2}$ Throughout the paper we refer to interest rates and yields interchangeably.
} 
fundamentals, central banks can take an active role in containing it. ${ }^{3}$ Indeed, during the Great Recession, many central banks across the world have taken this position. They have achieved this by communicating policies that inhibit uncertainty about the path of short-term interest rates (i.e., forward guidance).

With respect to the literature, our paper is closely related to Creal and $\mathrm{Wu}$ (2016), who investigate the relationship between uncertainty about interest rates and economic fluctuations, for the US. Their interest rate uncertainty is extracted from the volatility factors of a term structure model with macro variables, thus rendering it an objective measure of uncertainty. The effect of this type of uncertainty on selected macro variables (inflation and unemployment) is then investigated through a VAR model with stochastic volatility. Our paper complements on answering similar questions with subjective measures of interest rate uncertainty. Importantly, in our paper, assumptions for identification are defended via the design of surveys. We provide this analysis for a number of countries with different economic structures and monetary policies, allowing for interesting comparisons. Furthermore, while Creal and $\mathrm{Wu}$ (2016) mostly focus on long-yield uncertainty, we also study the effects of subjective short-yield uncertainty and find that it has stronger quantitative effects than uncertainty about the long yield. In addition, with regard to the construction of the uncertainty measure, a similar approach has also concurrently been used by Ozturk and Sheng (2016). While we focus on interest rate uncertainty for selected developed countries, Ozturk and Sheng (2016) study the effects of aggregate macro uncertainty (based on several nominal and real economic indicators) in a country-specific and a global setting. Furthermore, we also explore the cross-country differential effects of interest uncertainty shocks based on country-specific economic structures and institutional frameworks.

The paper is structured as follows. In Section 2 we introduce subjective uncertainty measures of interest rates and stylized facts. In Section 3 the VAR modeling framework, the identification strategy and results are presented. Finally, we conclude in Section 4.

\section{Subjective interest rate uncertainty}

The following section provides a summary of the survey-based uncertainty measures available in the literature. Subsequently, we present the measure we opt for in order to build our interest rate uncertainty.

\subsection{Measuring survey-based uncertainty}

Subjective measures are typically obtained via survey forecasts of professionals and/or households. The information provided varies substantially from one survey to another and includes a range of the following: consensus information, individual point estimates, and individual probability distributions. Based on this information,

\footnotetext{
${ }^{3}$ In a model where central banks, firms and households have imperfect information about the current state of the economy, Eusepi and Preston (2010) show that communication allows agents to construct more accurate forecasts, leading to greater stability in observed output, inflation, and nominal interest rates.
} 
three subjective measures of uncertainty have been predominantly represented in the literature: i) the disagreement among forecasters, ii) the average individual forecast error variance, and iii) the variance of the surveys' aggregate probability distribution (scarcely available). From the aforementioned list, the last measure is the most informative on uncertainty. This measure assigns probabilities to the given forecasts, thus converging towards the notion of Knightian uncertainty, in which even probabilities cannot be pinned down. However, few surveys report these individual histograms. For that reason, measures of uncertainty have been constructed based on a more limited information set.

One of the most common survey-based uncertainty proxies in the literature is the disagreement of forecasters (e.g., Boero et al., 2008; Rich and Tracy, 2010). The literature starts from the premise that disagreement is positively correlated with uncertainty (see Zarnowitz and Lambros, 1987; Giordani and Soderlind, 2003). However, there are several known caveats associated with disagreement as a proxy for uncertainty. Differences in opinion, rather than uncertainty, may be more likely reflected in the disagreement of survey forecasts (e.g., Diether et al., 2002; Mankiw et al., 2004). Lahiri and Sheng (2010) show that, even if forecasts are unbiased, the disagreement in forecasters' point estimates does not equal forecast error uncertainty unless the variance of accumulated aggregate shocks over the forecast horizon is zero. They further show, that the reliability of disagreement as a proxy for uncertainty is contingent on the stability of the forecasting environment and the length of the forecast horizon. D'Amico and Orphanides (2014) also find disagreement to be a poor proxy for forecast uncertainty, thus reinforcing arguments for the exploitation of uncertainty measures similar to those in Lahiri and Sheng (2010). ${ }^{4}$ The latter show that aggregate forecast uncertainty can be expressed as the disagreement among forecasters plus the perceived variability of future aggregate shocks. These components are thought to represent idiosyncratic and common uncertainty, respectively. We base our interest rate uncertainty measure on this approach, which we introduce below.

Let us denote by $U_{t}^{x}(h)$ the $h$-period ahead uncertainty in the variable $x_{t}$. Also, we define by $F_{i, t+h \mid t}$ the $h$-period ahead forecast of $x_{t}$ of the $i$ th survey participant, where $h$ is the forecast horizon, $i=1, \ldots, N$ and $N$ is the number of forecasters participating in period $t$ 's survey. Let $F_{., t+h \mid t}$ be the mean forecast across individual forecasters. The measure of $U_{t}^{x}(h)$ is the sum of two components:

$$
U_{t}^{x}(h)=D_{t}^{x}(h)+V_{t}^{x}(h) .
$$

where $D_{t}^{x}(h)$ represents disagreement among professional forecasters, computed as $D_{t}^{x}(h)=\frac{1}{N} \sum_{i=1}^{N}\left(F_{i, t+h \mid t}-F_{., t+h \mid t}\right)^{2}$, and $V_{t}^{x}(h)=\sigma_{t+h \mid t}^{2}$ represents the conditional variance of mean forecast errors $e_{t+h}$.

The mean forecast error is given by:

$$
e_{t+h}=\frac{1}{N} \sum_{i=1}^{N}\left(x_{t+h}-F_{i, t+h \mid t}\right) .
$$

Lahiri and Sheng (2010) suggest that in order to construct a robust, ex ante

\footnotetext{
${ }^{4}$ Lahiri and Sheng (2010) target inflation and output uncertainty.
} 
measure of uncertainty, the information set of the econometrician should be aligned with the information available to the forecaster at time $t$. That is, the forecast error used to extract the variance of aggregate shocks at time $t$, should not include the $t+h$ realizations of the forecast. This necessitates the estimation of $V_{t}^{x}(h)$ conditional on past information. Lahiri and Sheng (2010) estimate it using GARCH-type models with various distributional assumptions on the filtered mean forecast errors.

However, with GARCH-type models the evolution of $V_{t}^{x}(h)$ is not stochastic. To our purpose, we would like to study the effects of shocks to uncertainty therefore it is important for $V_{t}^{x}(h)$ to be time-varying and stochastic. We thus propose a stochastic volatility model on the mean forecast errors that allows for a shock to the second moment that is independent of the first moment, consistent with theoretical models of uncertainty. We estimate $V_{t}^{x}(h)$ using a standard stochastic volatility model in the spirit of Taylor (1994) and Harvey et al. (1994). ${ }^{5}$

\section{$2.2 \quad$ Interest rate uncertainty and its dynamics}

We use global macroeconomic survey data provided by Consensus Economics, which polls both public and private economic institutions. These surveys are published on a monthly basis. Consensus Economics reports the point estimates of individual forecasters for several macroeconomic variables. To our interest, we exploit shortand long-term interest rate forecasts. In the survey, responders are asked to provide their forecast on the 3-month and 10-year government bonds' interest rates. ${ }^{6}$ These estimates are available at two forecast horizons, 3-months and 12-months ahead. We will exploit the 3-month ahead forecasts for the short- and long-term interest rate maturities. $^{7}$

In the following, we will often refer to uncertainty measures as $U_{t}^{\text {short }}(h)$ and $U_{t}^{\text {long }}(h)$ for $h=3$ months and where short and long refer to 3-month and 10-year Government bonds' yields, respectively. Starting from the individual point estimates and using Eq. 1, we build uncertainty measures for the US, Japan, the UK, Germany, France, Italy, Spain, Canada and Sweden. Our first data point starts in January 1993 for the US, Japan, the UK and Canada and in January 1995 for Sweden. For all euro area countries, measures of uncertainty on short yields are available from January 1999 onwards. Before this date, surveys asked about country-specific interbank rates. With the creation of the euro area, surveys collect forecast on the common interbank rate (i.e., Euribor). Measures of long-yield uncertainty are available since January 1993, for Germany, France and Italy and since January 1995 for Spain. Our sample ends in August 2015. To construct the forecast errors we use equivalent realized data on interest rates for each country/area, obtained from

\footnotetext{
${ }^{5}$ We opt for a parsimonious specification of the stochastic volatility model and $\hat{V}_{t}^{x}(h)$ is computed using filtered estimates rather than smoothed ones, to align the information set of the econometrician to that of the forecasters.

${ }^{6}$ In different countries the exact term might change, for example, in the US, CE refers to Treasury Bill Rate and Treasury Bond Rate, respectively. Note that in CE surveys, 3-month yields refer to interbank rates in the case of the UK, Japan, Sweden and euro area countries, while 10-year yields all refer to government bonds.

${ }^{7}$ Similar analysis has been done on 12-month ahead forecasts for the short- and long-term interest rate maturities. Results are qualitatively similar and are available upon request.
} 
Table 1: Descriptive statistics for CE forecasts on short and long yields, 3-month ahead horizon

\begin{tabular}{lccccccccc}
\hline & US & Japan & Germany & France & UK & Italy & Canada & Spain & Sweden \\
\hline \hline 3 month yield & & & & & & & & & \\
\hline CE mean & 2.75 & 0.60 & 2.30 & 2.26 & 4.46 & 2.39 & 3.14 & 2.34 & 3.25 \\
CE std & 2.22 & 0.70 & 1.52 & 1.50 & 2.24 & 1.52 & 1.90 & 1.52 & 1.93 \\
Realized mean & 2.64 & 0.37 & 2.24 & 2.24 & 3.64 & 2.24 & 2.54 & 2.24 & 2.83 \\
Realized std & 2.22 & 0.63 & 1.59 & 1.59 & 2.42 & 1.59 & 1.66 & 1.59 & 2.08 \\
$U_{t}^{x}(h)$ mean & 0.11 & 0.05 & 0.09 & 0.09 & 0.14 & 0.09 & 0.16 & 0.09 & 0.12 \\
$D_{t}^{x}(h)$ mean & 0.04 & 0.01 & 0.03 & 0.03 & 0.05 & 0.02 & 0.06 & 0.03 & 0.04 \\
Corr $\left(U_{t}^{x}(h), D_{t}^{x}(h)\right)$ & 0.91 & 0.80 & 0.86 & 0.87 & 0.86 & 0.77 & 0.86 & 0.93 & 0.97 \\
\hline 10 year yield & & & & & & & & & \\
\hline CE mean & 4.54 & 1.78 & 4.13 & 4.42 & 5.25 & 5.39 & 4.78 & 4.97 & 4.43 \\
CE std & 1.57 & 1.02 & 1.65 & 1.62 & 1.89 & 2.36 & 1.88 & 1.97 & 2.03 \\
Realized mean & 4.41 & 1.70 & 4.01 & 4.26 & 4.74 & 5.50 & 4.62 & 4.96 & 4.28 \\
Realized std & 1.58 & 1.03 & 1.75 & 1.67 & 1.87 & 2.55 & 1.93 & 2.00 & 2.21 \\
$U_{t}^{x}(h)$ mean & 0.24 & 0.13 & 0.23 & 0.19 & 0.28 & 0.29 & 0.28 & 0.26 & 0.29 \\
$D_{t}^{x}(h)$ mean & 0.06 & 0.03 & 0.04 & 0.06 & 0.06 & 0.10 & 0.07 & 0.10 & 0.06 \\
Corr $\left(U_{t}^{x}(h), D_{t}^{x}(h)\right)$ & 0.99 & 0.83 & 0.17 & 0.97 & 0.34 & 0.92 & 0.37 & 0.99 & 0.47 \\
\hline
\end{tabular}

Bloomberg.

Table 1 displays summary statistics for CE forecasts on short and long yields at a 3 -month ahead horizon, their respective realized data, disagreement $D_{t}^{x}(h)$ and our uncertainty measure $U_{t}^{x}(h)$. We observe that the forecasted yield curve is upward sloping, preserving the feature of realized yields that also tend to be upward sloping on average (i.e. the average 10-year yields forecasts are higher than those for the 3 -month yields). Furthermore, the short-end of the forecasted yield curve is more volatile than the long-end in the US, the UK and Canada. However, this feature dissipates in Japan, Sweden and the four euro area countries. On the one hand, Japan is a particular case in its own right due to the fact that short yields have been constrained by the zero lower bound for almost two decades. On the other hand, euro area countries have the particularity of their short-end of the yield curve being the common interbank rate while the long-end of the yield curve is country-specific and given by their individual 10-year Government bonds. The US, the UK and Sweden display the highest level of volatility in actual and CE forecasts at the short-end of the yield curve, in our sample. Among the countries with high volatility at the long-end of the yield-curve, countries that have struggled with the sustainability of their public finances, such as Italy and Spain, rank high on the level and volatility across actual and CE forecasts. In contrast, Japan has the lowest levels of realized interest rates within our sample, which is also reflected by having the lowest level and volatility in CE forecasts.

With respect to interest rate uncertainty, measures on the 10-year yields are higher than on 3-month yields. Interestingly, euro area countries share, on average, a similar uncertainty on the interbank rate (i.e., short yield). Among these countries, the differences appear on the long-yield uncertainty which is more country-driven. Disagreement remains at similar levels across countries and across the maturity of yields. Average disagreement varies between 1 and 7 basis points, with the only exceptions being Italy and Spain, where average disagreement on long-term yields 
is about 10 basis points.

Figures 1 and 2 report graphical representations of our uncertainty measure $U_{t}^{x}(h)$ for all countries, for the 3-month and 10-year yields, respectively. Overall, we observe that interest rate uncertainty varies over time. Across countries, we observe common spikes (predominantly on short-term yield uncertainty) pertaining mostly to the recent financial crisis, but also substantial individual variation. For instance, the US displays high levels of short-term interest rate uncertainty around the post dot-com bubble and after the September 11 attacks. For most countries, uncertainty on long-term yields appears to be noisy, except for Italy and Spain. These countries have been strongly affected during the 2011-2013 European sovereign debt crisis and the pressure exerted on their long-term yields is reflected in their corresponding uncertainties which reach their highest peak during that period. Moreover, we observe that zero-lower-bound environments are characterized by periods of low uncertainty, as in the case of Japan (for the early 2000s), the US and the UK (since 2009), and euro area countries (since late 2012).

Figure 1: Subjective short-term interest rate uncertainty
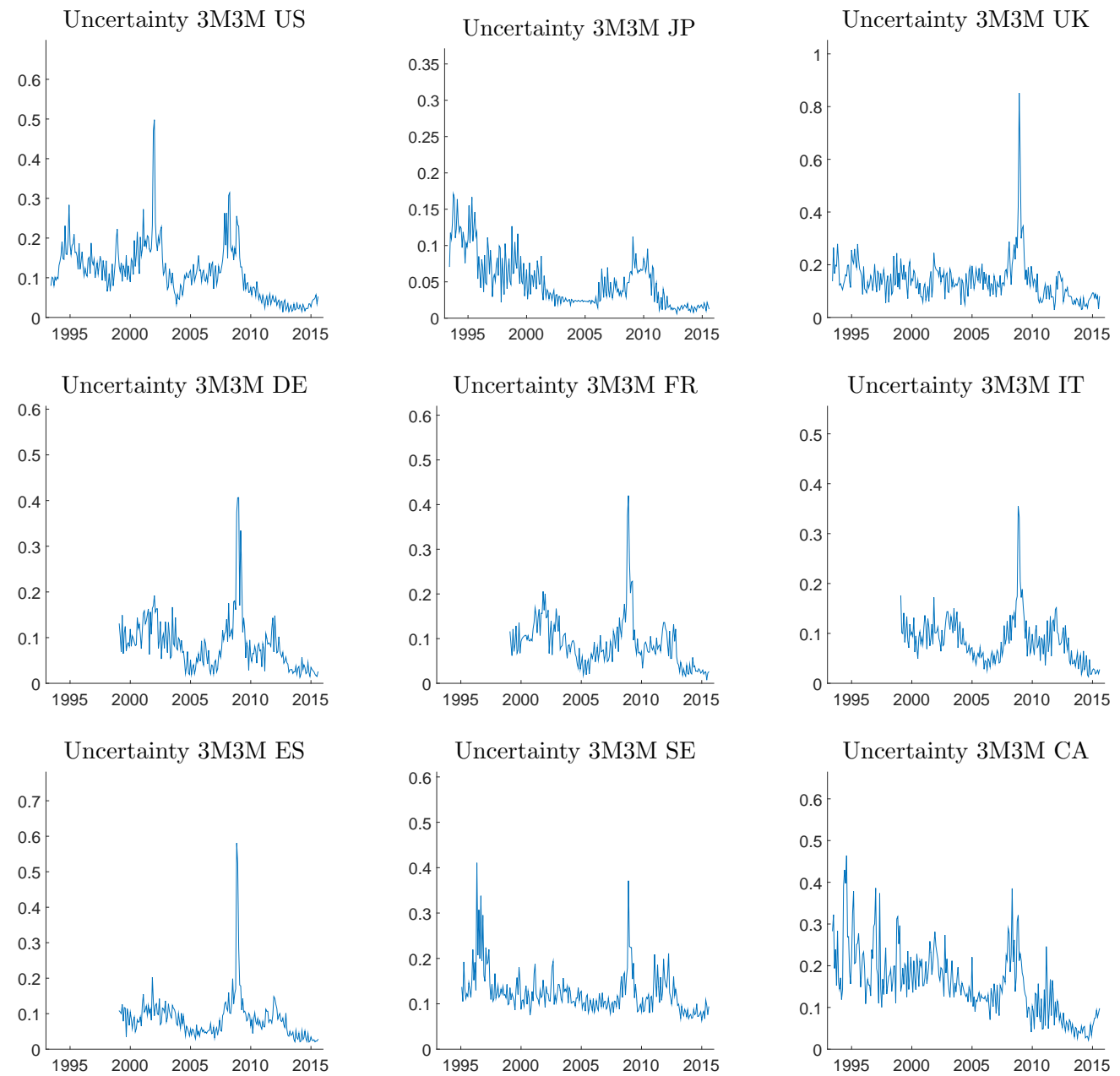

Notes: Interest rate uncertainty measure, $U_{t}^{x}(h)$, for all countries, for the 3-month yields, at a 3-month forecasting horizon. The label Uncertainty 3M3M refers to $U_{t}^{\text {short }}(h)$. US stands for the United States, JP for Japan, UK for the United Kingdom, DE for Germany, FR for France, IT for Italy, ES for Spain, SE for Sweden and CA for Canada. 
Figure 2: Subjective long-term interest rate uncertainty
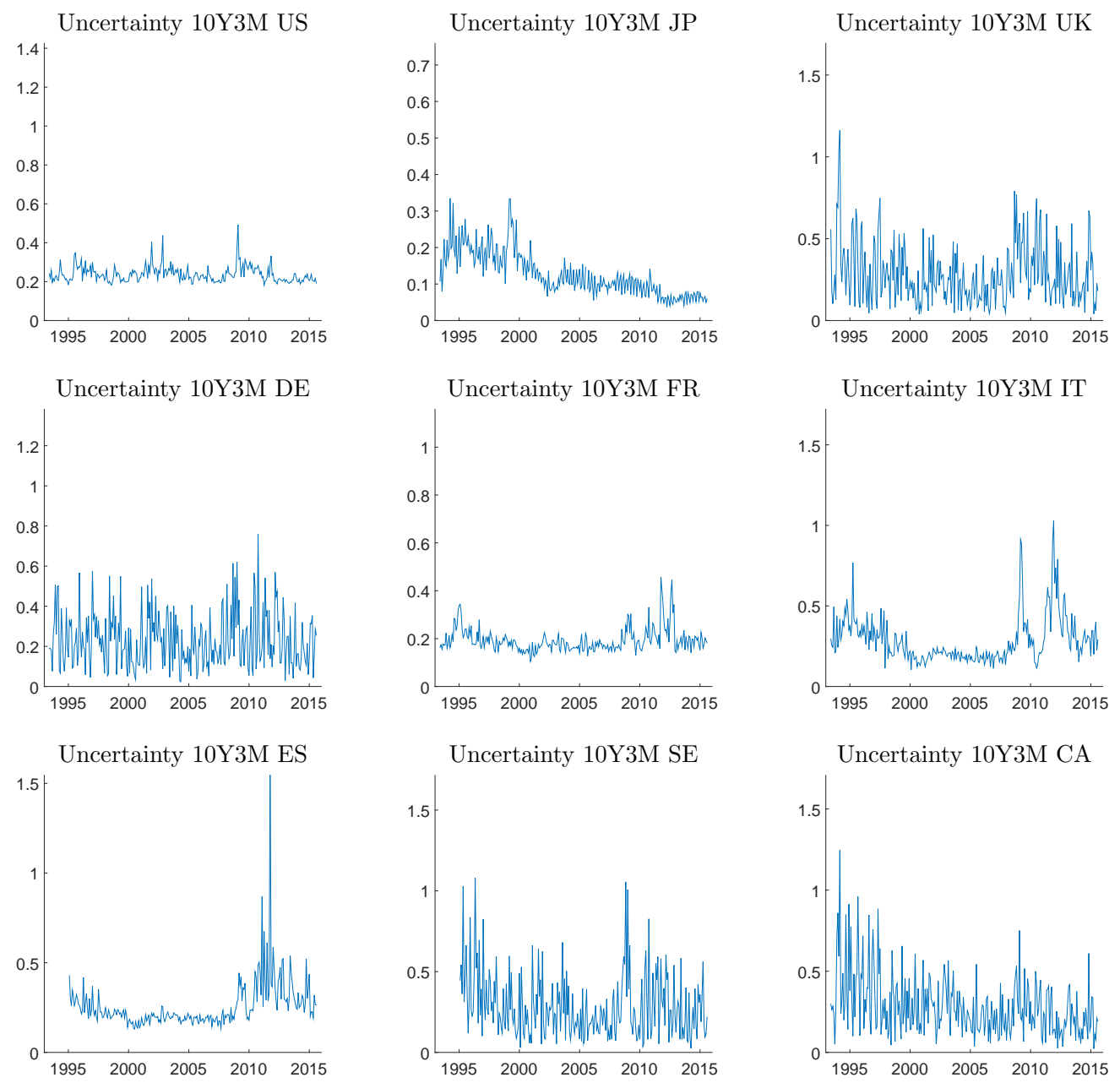

Notes: Interest rate uncertainty measure, $U_{t}^{x}(h)$, for all countries, for the 10-year yields, at a 3-month forecasting horizon. The label Uncertainty $10 \mathrm{Y} 3 \mathrm{M}$ refers to $U_{t}^{\text {long }}(h)$. US stands for the United States, JP for Japan, UK for the United Kingdom, DE for Germany, FR for France, IT for Italy, ES for Spain, SE for Sweden and CA for Canada. 
Figure 3 compares our measure of short-run interest rate uncertainty (the blue lines) with other well-known measures of uncertainty (the red lines) available in the literature, for the case of the US. More specifically we compare our measure with the VIX, the monetary policy uncertainty index (MPU) of Baker et al. (2016), and measures of macro and financial uncertainty as in Jurado et al. (2015) and Ludvigson et al. (2015). Several observations are worth noting. First, while other measures of uncertainty are relatively low during the first half of the 1990s, interest rate uncertainty and the MPU measure are more elevated, reaching the highest peak in the beginning of 2002, a period preceded by continuous reductions of Fed Funds rates (i.e., from 6.5 to 1.75 percent, in a time span of less than two years). Among other uncertainty proxies, only the MPU measure reflects high uncertainty during this period similar to our short-run interest rate uncertainty. Furthermore, after the mid-2000s, uncertainty about interest rates starts building up along with macroeconomic uncertainty while all other measures appear to be at their lowest levels. Uncertainty as measured by financial proxies catches up with a delay and drastically increases by the end of 2007.

Figure 3: Subjective interest rate uncertainty in US vs. other measures
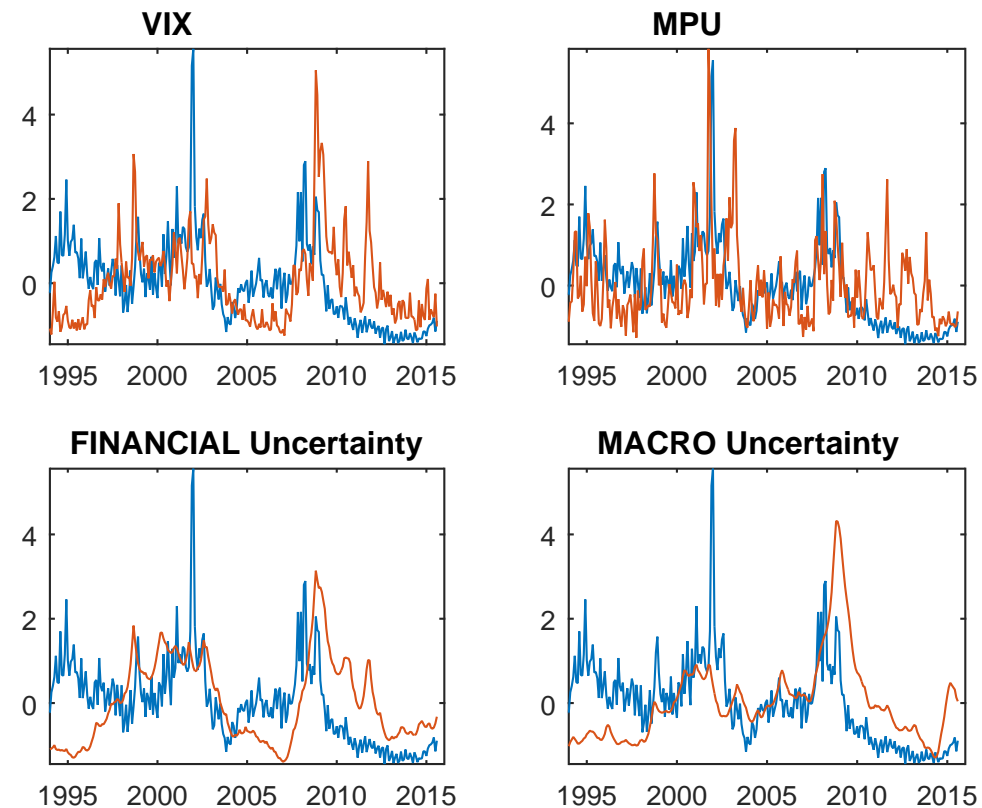

Notes: MPU denotes the Baker et al. (2016) index of monetary policy uncertainty based on news coverage. Financial and Macro uncertainty refer to Jurado et al. (2015)'s measures. Financial uncertainty is measured as the common uncertainty stemming from 147 of monthly financial indicators. Macro uncertainty is measured as the common uncertainty stemming from 134 macroeconomic time series. Our subjective interest rate uncertainty measure for the US refers to the 3-month yield, at a 3-month forecasting horizon. All measures are standardized.

Moreover, at the height of the Great Recession of 2008, while all uncertainty measures continue rising, the uncertainty about interest rates and the MPU index are falling. This reflects the reach of the zero lower bound (ZLB) on nominal interest rates and forward guidance communications by the Fed to keep rates low for long. ${ }^{8}$ With interest rates at the ZLB, heightened monetary policy uncertainty in

\footnotetext{
${ }^{8}$ Forward guidance communication by the Fed has undergone several changes ranging from
} 
the following years reflects uncertainty around quantitative easing programs, the tapering tantrum and lift-off expectations. The above-mentioned observations reveal that interest rate uncertainty is of a particular nature. In some periods it is consistent with macro uncertainty (i.e., in line with fundamentals) and uncertainty in financial variables. However, up to the ZLB, our measure is more in line with the MPU index, suggesting that short-run interest rate uncertainty is a good proxy for monetary policy uncertainty in the US for this period. Once at the ZLB, interest rate uncertainty no longer reflects uncertainty about monetary policy in general.

\section{Interest Rate Uncertainty and the Macroecon- omy}

In this section, we introduce the modeling approach and identification used to investigate the effect of subjective interest rate uncertainty for our selected countries. This is followed by a discussion of results and a cross-country comparison.

\subsection{Modeling Framework and Identification}

In the following we investigate the dynamic responses of selected key macroeconomic variables to innovations to subjective interest rate uncertainty. To this aim we estimate individual structural VAR models for the US, Japan, the UK, Germany, France, Italy, Canada, Spain and Sweden. The VAR model has a standard representation as below:

$$
y_{t}=A_{0}+A_{1} y_{t-1}+\ldots+A_{p} y_{t-p}+B_{0} z_{t}+u_{t}
$$

for $t=1, \ldots, T$, where $y_{t}$ is a $n \times 1$ vector of endogenous variables, $z_{t}$ is a $m \times 1$ vector of exogenous variables, and $u_{t}$ represents the reduced-form errors,

$$
u_{t} \mid y_{t-1} \sim \text { iid } N(0, \Sigma) .
$$

Our estimations include the following vector of endogenous variables: $y_{t}=$ $\left(U_{t}^{x}(h), i p_{t}, \pi_{t}, \pi_{t}^{d}, r t_{t}, u r_{t}\right)$, with $U_{t}^{x}(h)$ being the interest rate uncertainty measure, $i p_{t}$ the $(\log )$ of the industrial production index, $\pi_{t}$ the CPI inflation rate, $\pi_{t}^{d}$ the producer price $(\mathrm{PP})$ inflation, $r t_{t}$ the $(\log )$ of retail trade and $u r_{t}$ being the unemployment rate. The individual VARs also include a constant, a time trend and oil prices as an exogenous variable. We estimate two versions of this VAR for each country with uncertainty pertaining to either the short yield, $U_{t}^{\text {short }}(h)$, or the long yield, $U_{t}^{\text {long }}(h)$, for the 3 -month ahead forecasts.

The literature discusses several channels through which uncertainty can affect the economy, either through the precautionary saving motive or the wait-and-see mechanism on investment and on hiring and firing decisions of firms. For instance, in the presence of partial irreversibility, higher uncertainty increases the real option value of waiting and firms scale back their investment and hiring plans (see Bernanke, 1983; Dixit and Pindyck, 1994, among others). In this context, our choice of variables

open-ended to state-dependent formulations. 
in the VAR is a good compromise between having a parsimonious (monthly) VAR and also being able to get an impression on the channels through which the effects of interest rate uncertainty are transmitted to the economy.

At this stage an important question arises on the identification strategy. Even though the empirical literature on uncertainty has rapidly evolved in recent years, there is still no consensus as of yet, on how to best identify shocks to uncertainty. Most of the literature on the macroeconomic effects of uncertainty, including important contributions (see Bachmann et al., 2013; Baker et al., 2016; FernandezVillaverde et al., 2015; Jurado et al., 2015, among others), identifies uncertainty shocks using the recursive Cholesky decomposition, which assumes a particular ordering of the variables in the VAR. ${ }^{9}$ Depending on the ordering, one of the two assumptions is made: (i) uncertainty does not contemporaneously respond to macroeconomic shocks, (ii) the macroeconomy does not contemporaneously respond to uncertainty. However, in these papers none of the two assumptions is defended either based on theoretical grounds or on the way the proxy measures of uncertainty are constructed. Given this drawback, the strategy has been to check different permutations in robustness exercises.

Nevertheless, the econometrician can defend particular assumptions on the ordering of variables when data used in the VAR are generated with a consistent, temporal order within a period. This situation could arise when using survey data. Typically, the timing when surveys are filled varies within a period (i.e., beginning of the month, middle or end of the month). The econometrician can use this information to guide assumptions for identification. With regard to uncertainty literature, Leduc and Liu (2016) is an example where the timing advantage of Michigan survey data relative to the timing of macroeconomic data releases is used to identify the effects of consumer uncertainty shocks on the macroeconomy. Leduc and Sill (2013) and Kilian and Vega (2011) are other examples in the literature where the timing of surveys is used in order to assess the role of shocks to expected future economic activity on economic fluctuations.

Given that we also work with survey data, we can take advantage of the temporal ordering of the data used in the analysis to guide our identification strategy. More specifically, CE surveys are of a monthly frequency and forecasts are made generally within the first 10 days of the month. During this period, contemporaneous monthly data on economic activity are not known. Typically, the first indicators on industrial production, prices and employment situation for a particular month start to become available only during the second part of the month. If we look at January 2017 as an example, the CE surveys have their deadline on January 9th. For the US, the Bloomberg Economic Calendar shows that the first information for January 2017 will be the Redbook Index released on January 10, followed by information on Mortgage applications on January 11 and on Jobless claims on January 12, all referring to the first week of January. ${ }^{10}$ Additional, preliminary information on in-

\footnotetext{
${ }^{9}$ In addition to the recursive Cholesky decomposition, Bachmann et al. (2013) have used longrun restrictions to identify uncertainty shocks. Furthermore, Ludvigson et al. (2015) propose a structural VAR with external instruments to help with identification. Nonetheless, as well known in the microeconometrics literature, the success of the instrumental variables' approach depends heavily on the choice of external instruments.

${ }^{10}$ The Redbook is a sales-weighted measure of the growth in sales in a store year-over-year,
} 
dustrial production, prices and economic sentiment is scheduled to arrive after the third week of the month. For other countries in our sample, this information typically arrives from the third week onward (i.e., Eurostat Release Calendar for Euro indicators shows January 30 as the earliest date of release for economic indicators for January 2017).

Therefore, by construction, the CE forecasters' information set at time $t$ includes only past realizations of macroeconomic data like industrial production, prices, and unemployment when surveys are filled out. As such, the temporal ordering of the data justifies a recursive identification scheme where uncertainty can affect real activity contemporaneously but not vice versa. This identification strategy places interest rate uncertainty measure first in the VAR ordering, i.e., exogenous innovations to uncertainty can have an immediate impact on macro variables but uncertainty will respond with a lag to other innovations. The order of the remaining variables does not matter when interested (only) in the effect of shocks to interest rate uncertainty (see Christiano et al., 1999).

The VARs are estimated on a data set spanning the period 1993:1-2015:8 for the US, Japan, the UK and Canada and 1995:1-2015:8 for Sweden. As discussed previously, for the euro area, the VARs with short-yield uncertainty are estimated for the period 1999:1-2015:8 and those for the long yield for the period 1993:1-2015:8 (except for Spain, 1995:1-2015:8). The source of the macro data for each country is Datastream and the OECD. We employ Bayesian techniques for estimation, following Uhlig (2005). The VAR coefficients are drawn from a normal-inverse-Wishart distribution with a flat prior. ${ }^{11}$ The optimal lag is selected based on the BIC information criteria. ${ }^{12}$ We provide inference through the median response and its 68 percent posterior distribution, based on 2000 draws.

\subsection{Results and Discussion}

In the following we present the results from the estimation of country-specific Bayesian VARs. We start first by showing the results for the US as it is the most studied case and we can compare our findings with the literature. Then we show results for other countries in groups: Euro area (DE, FR, IT, ES), Inflation targeting (UK, SE, CA) and Others (US, JP). Following the literature (see Bloom, 2009; Jurado et al., 2015, among others) we show responses to big uncertainty shocks, corresponding to four standard deviations. ${ }^{13}$

Figure 4 shows impulse responses to innovations to short and long-yield uncertainty (first and second row, respectively) for the US. The black solid line denotes the point-wise posterior median impulse response and the shaded area represents the corresponding 68 percent posterior distribution. We observe that shocks to interest rate uncertainty are recessionary; they reduce production and prices and increase

derived from a sample of large US general merchandise retailers that represent approximately 9,000 stores. The Redbook Index is a weekly survey measure.

${ }^{11} \mathrm{~A}$ flat prior allows us to use the benefits of the Bayesian techniques while allowing our results to be more data-driven.

${ }^{12}$ Throughout our estimations, the optimal lag selected fluctuates between 2 and 3 lags.

${ }^{13}$ In our sample, this shock size is in general below the level we observe for both measures of interest rate uncertainty in all countries under our study. 
unemployment. In terms of magnitudes, short-yield uncertainty causes a drop in industrial production of about 1.7 percent within the year the shock hits and the recovery takes more than two years. This result is in contrast to the "sharp drop and rapid rebound" of the economy in response to VIX uncertainty as shown in Bloom (2009). Instead, it is in line with Jurado et al. (2015) where shocks to (objective) uncertainty induce a drop in production of similar magnitudes and persistence as under our investigation. In addition, we observe that the retail trade component of demand falls but not as strongly as the drop in industrial production. This finding is in line with the premise that the precautionary saving channel of uncertainty is expected to be stronger on the consumption of durable goods rather than on the consumption of food and beverages.

Figure 4: IRFs to interest rate uncertainty shock, the US
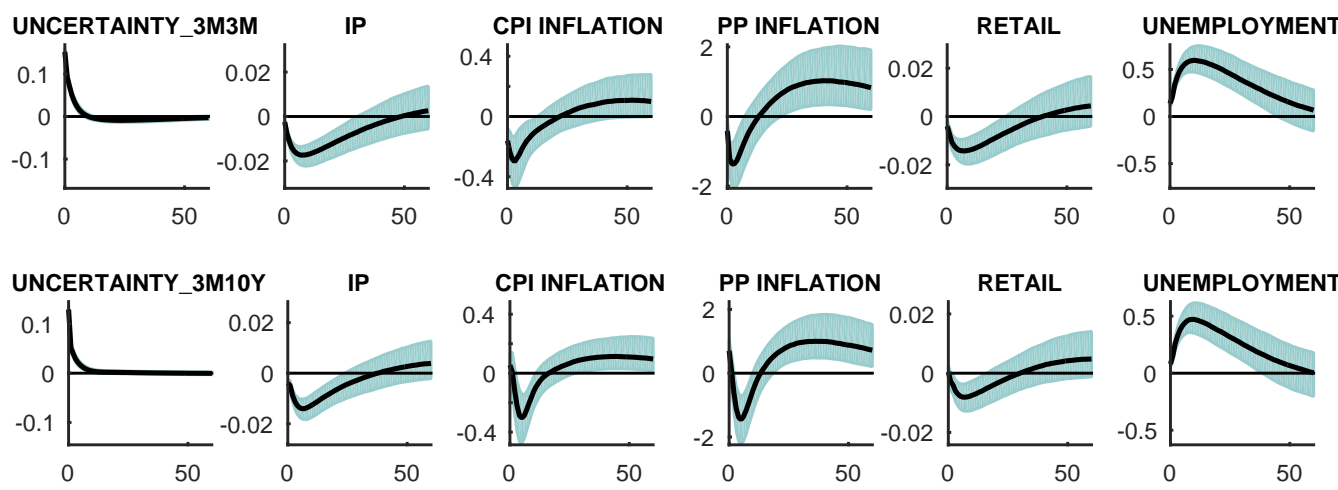

Notes: The solid line in black denotes median impulse response from the estimated BVARs with $y_{t}=$ $\left(U_{t}^{x}(h), i p_{t}, \pi_{t}, \pi_{t}^{d}, r t_{t}, u r_{t}\right)$. VARs include an exogenous variable, oil prices, a constant and a time trend. The shaded area corresponds to the 68 percent error band. Uncertainty_3M3M and Uncertainty_3M10Y refer respec-

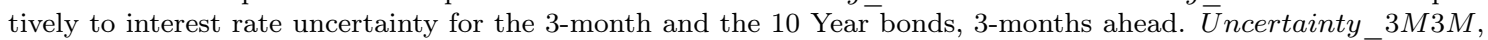
Uncertainty_3M10Y, IP (Industrial Production) and Retail (retail trade) enter in levels and CPI inflation, PPI inflation and unemployment in rates, in percent. Horizontal axis is in months.

With regards to prices, we observe that producer price inflation drops sharply by 1.4 percentage points while CPI inflation drops by a smaller magnitude. Furthermore, the unemployment rate increases significantly and persistently, reaching a peak of 0.6 percentage points, within a year. The recovery back to the steady state is slow, taking about five years. Similar effects are observed in the second panel of Figure 4 in response to shocks to long-yield uncertainty. A slight difference is observed in the magnitudes of the responses which are smaller than for the short-yield uncertainty shock. In addition, the rebound in prices and output is quicker, cutting thus recovery time by one year in the case of output and six months in the case of CPI inflation.

These findings match well and confirm previous results in the empirical literature of uncertainty for the case of the US (see Caggiano et al., 2014; Jurado et al., 2015, among others). These results are also in line with predictions of models with nominal and real rigidities. For instance, the model of Leduc and Liu (2016) with sticky prices and labor market frictions suggests a demand and a wait-and-see channel through which the effects of uncertainty are propagated. In this model, uncertainty leads to a decline in aggregate demand which further reduces producer prices and therefore firm profits. This effect leads to a lower probability of a new match in the labor market 
which induces firms to post fewer job vacancies, pushing the unemployment rate up. As more unemployed workers fail to find a job match, household incomes decline further. This leads to an even greater fall in aggregate demand, which magnifies the effects of uncertainty shocks. In addition, search frictions increase unemployment via the wait-and-see mechanism. With search frictions, a job match represents a longterm employment relationship that is irreversible. Under uncertainty, the option value of waiting increases and the match value declines. Firms respond by reducing hiring, therefore contributing to a further increase in unemployment.

Figure 5: IRFs to short interest rate uncertainty shock across countries
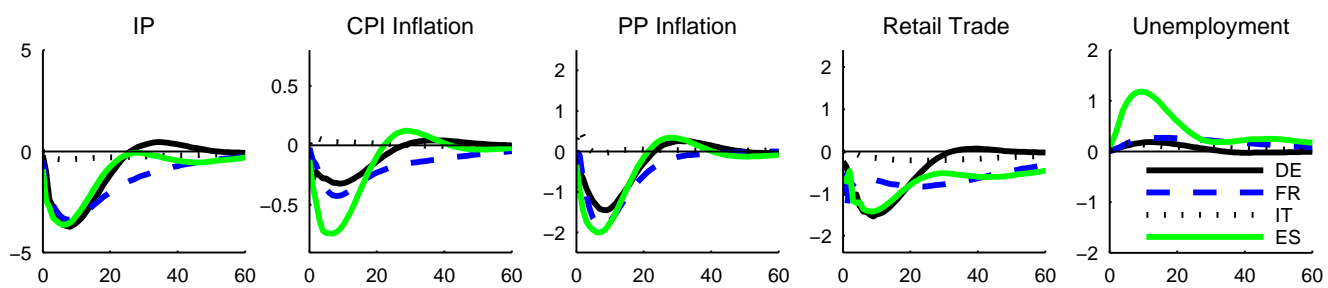

Euro Area (DE, FR, IT, ES)
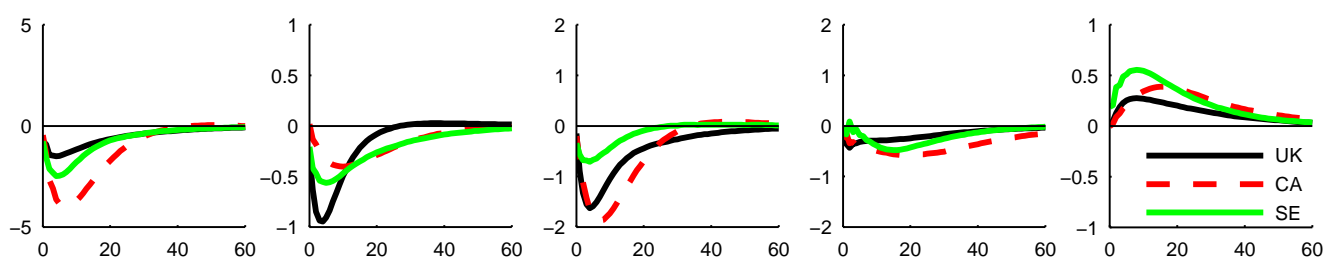

Inflation Targeting (UK, CA, SE)
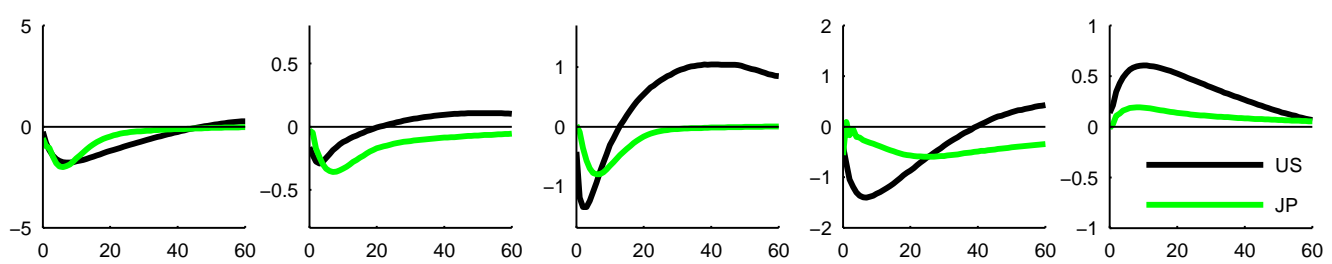

Others (US, JP)

Notes: IRFs to interest rate uncertainty for the 3-month rate, 3-months ahead. The solid line in black denotes median impulse response from the estimated BVARs with $y_{t}=\left(U_{t}^{x}(h), i p_{t}, \pi_{t}, \pi_{t}^{d}, r t_{t}, u r_{t}\right)$. VARs include an exogenous variable, oil prices, a constant and a time trend. The response of IP (Industrial Production) and Retail (retail trade) are in percent and for prices and unemployment rate in percentage points. Horizontal axis is in months.

Figure 5 compares the (median) responses of our macro variables to the shortyield uncertainty shock across different countries. ${ }^{14}$ Generally, we observe similar qualitative results and mechanisms at play as those described for the US. Across all countries, the short-yield uncertainty shock has both recessionary and deflationary effects, resembling a demand shock. The magnitudes and the persistence of responses are considerable. Overall, there is substantial heterogeneity across countries, especially with respect to the effects on prices and unemployment rates. This

\footnotetext{
${ }^{14}$ For ease of comparison we do not plot the $68 \%$ posterior credible bands. Similarly to figure 4 , all responses are significant with the exception of Italy and Japan.
} 
might reflect different degrees of nominal and real rigidities at work. The drop in production varies from 0.4 to 3.8 percent within the year the shock hits. In addition, we do not observe signs of overshooting or of rebounds on economic activity in response to interest rate uncertainty for any of the countries under study. Instead, the recovery of output to initial levels is slow, taking about 3 to 5 years. Retail trade is consistently less responsive to the shock than industrial production; it falls with delay and recovery is slow.

Unemployment worsens in response to interest rate uncertainty, with rates increasing between 0.15 and 1.2 percentage points. For most of the countries this increase is quite persistent and the reversion to initial levels takes longer than for output. Interestingly, the effect on unemployment is the lowest for Italy, Germany and Japan and not as sharply estimated as for the other countries. The effect on unemployment is the highest for Spain, about 1.2 percentage points. With respect to prices, in all countries (except Italy), CPI and PP inflation fall in response to interest rate uncertainty shocks. Also, producer prices consistently fall more sharply and by higher magnitudes compared to consumer prices. The drop in producer price inflation is at around 1.5 percentage points for Germany, France, Spain, the UK and the US. The fall in CPI inflation is more pronounced in the UK reaching roughly 0.9 percentage points and for other countries it varies from 0.3 to 0.5 percentage points.

With regards to the two measures of interest rate uncertainty, (see Figure 9 in the Appendix A), variation across countries appears mostly on the quantitative side, and occasionally but not significantly on the qualitative side, like for Spain and Japan. This result might reflect a different persistence of uncertainty measures to their own shocks. The response of short-yield uncertainty is small in magnitude but more persistent compared to the response of the long-yield uncertainty. In fact, the latter does not exhibit any persistence especially for the US, the UK, Germany, Spain and Italy.

As a robustness check, we also estimate BVARs for the US, the UK, Sweden and the euro area on samples that exclude periods were policy rates reached levels close to zero (i.e., low interest rate environments). ${ }^{15}$ Although it is not straightforward to define these periods, especially for Sweden and the euro area given their rates breached the zero lower bound, we opted for the following cut-off dates: December 2008 for the US, March 2009 for the UK and Sweden, and September 2014 for the euro area. Results are very similar to the full sample (see Figure 13 in the Appendix A). Worth noting, the effects of short-term interest rate uncertainty appear more persistent for the US with respect to prices and for France and Spain with respect to retail trade.

\subsubsection{Components of subjective interest rate uncertainty}

So far, we have studied the effects of shocks to our interest rate uncertainty measure on the economy. In Section 2, we introduced our interest rate uncertainty measure as the sum of two components, one being the disagreement among professional fore-

\footnotetext{
${ }^{15}$ Note that Japan and Canada have been excluded from this exercise as the former has been in a low interest rate environment for most of our sample and the latter does not clearly feature such environments.
} 
casters (representing idiosyncratic uncertainty) and the second component being the perceived variability of aggregate shocks (representing common uncertainty). Using the same VAR specification as the benchmark analysis, we now study the effects of the two components, separately. Figure 6 shows selected macro responses, namely those of industrial production and the unemployment rate. ${ }^{16}$ Overall, both shocks push the economy on the same direction. They tend to be contractionary to the economy, causing a slowdown in production and an increase in unemployment. Variations across these measures mainly appear on the magnitude and persistence of responses. All economies deteriorate immediately and rebound fast in response to disagreement shocks. The trough response for industrial production is observed within 6 months for all countries. In contrast, in response to common uncertainty, the economy slows down sluggishly but the troughs are on average larger and recoveries take longer. Ozturk and Sheng (2016) show that such differential effects prevail even when looking at macro uncertainty in a global setting.

Figure 6: IRFs to components of short interest rate uncertainty shocks

$$
\text { Disagreement Common Uncertainty }
$$
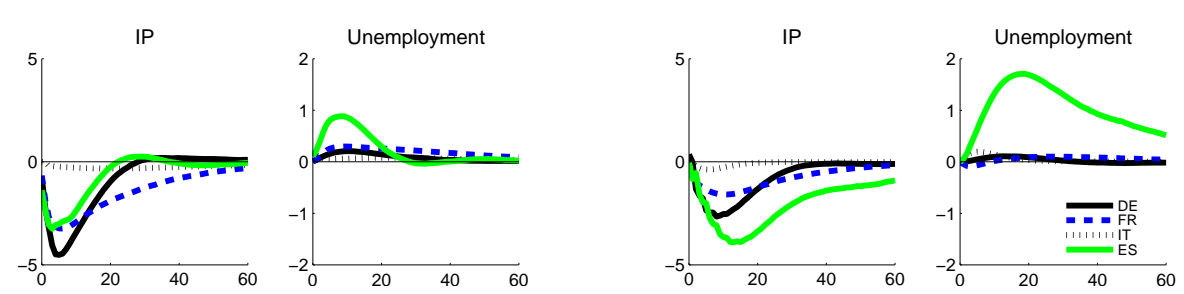

Euro Area (DE, FR, IT, ES)
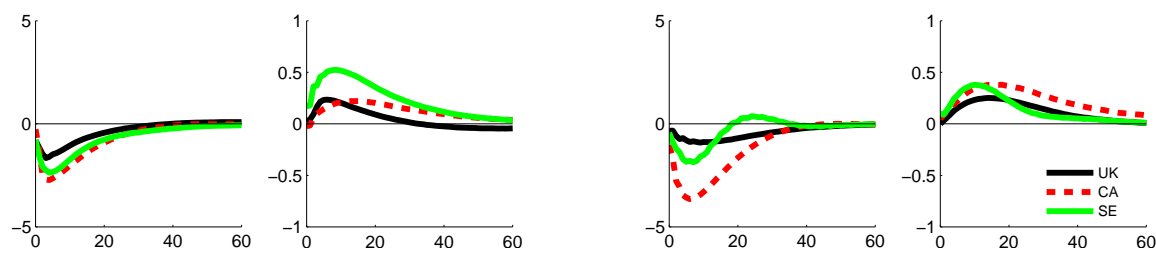

Inflation Targeting (UK, CA, SE)
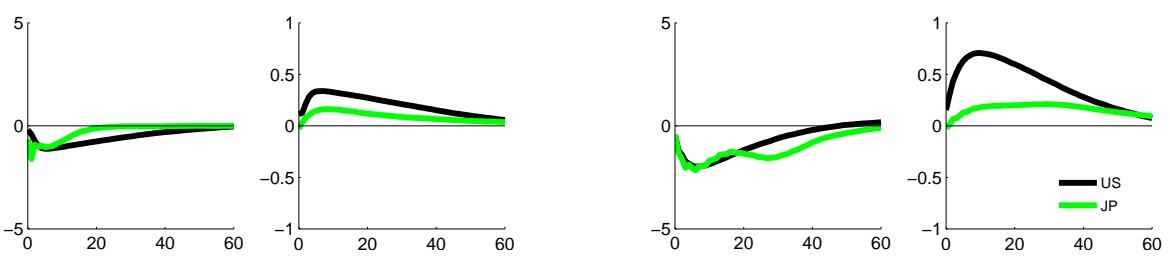

Others (US, JP)

Notes: IRFs in the first column, Disagreement, are estimated from country-specific VARs with $y_{t}=$ $\left.\left(D_{t}^{x}(h), i p_{t}, \pi_{t}, \pi_{t}^{d}, r t_{t}, u r_{t}\right)\right)$ and those in the second column, Common Uncertainty, are estimated from countryspecific VARs with $y_{t}=\left(V_{t}^{x}(h), i p_{t}, \pi_{t}, \pi_{t}^{d}, r t_{t}, u r_{t}\right)$. The solid line in black denotes median impulse response from the estimated BVARs with $y_{t}=\left(U_{t}^{x}(h), i p_{t}, \pi_{t}, \pi_{t}^{d}, r t_{t}, u r_{t}\right)$. VARs include an exogenous variable, oil prices, a constant and a time trend. The response of IP (Industrial Production) and Retail (retail trade) are in percent and for prices and unemployment rate in percentage points. Horizontal axis is in months.

\footnotetext{
${ }^{16}$ For the paper to be self-contained we do not show all the results of this analysis. They are available upon request.
} 


\subsubsection{Contribution of interest rate uncertainty shocks}

Having showed that interest rate uncertainty shocks have significant effects on the dynamics of our macro variables, we now focus on the quantitative importance of these shocks along the dimensions of the maturity of yields and across countries. To this aim, Table 2 reports the forecast error variance decomposition (FEVD), and more precisely, the maximum fraction of the posterior median of the FEVD, over a forecasting horizon of 60 months. Several observations are worth mentioning. Overall we see that uncertainty on the short yield has a larger peak contribution to the FEVD than uncertainty on the long yield. In terms of variables, interest rate uncertainty contributes substantially to variations in industrial production and unemployment, for most countries.

Table 2: FEVD (posterior median) of interest rate uncertainty shocks

\begin{tabular}{|c|c|c|c|c|c|c|c|c|c|}
\hline & US & Japan & Germany & France & UK & Italy & Canada & Spain & Sweden \\
\hline \multicolumn{10}{|l|}{$U_{t, 3 m}^{\text {short }}$} \\
\hline IP & 27.52 & 5.27 & 42.45 & 43.53 & 32.38 & 5.94 & 19.28 & 59.01 & 13.40 \\
\hline CPI inflation & 6.28 & 9.13 & 17.39 & 22.32 & 30.41 & 1.31 & 9.99 & 26.56 & 21.08 \\
\hline PPI & 8.97 & 9.09 & 23.89 & 25.08 & 7.48 & 1.52 & 7.85 & 32.01 & 5.21 \\
\hline Retail & 12.89 & 5.80 & 42.10 & 17.74 & 7.23 & 2.22 & 11.28 & 19.10 & 4.16 \\
\hline Unemployment & 39.71 & 12.44 & 7.15 & 22.71 & 18.68 & 8.23 & 19.53 & 43.09 & 31.70 \\
\hline \multicolumn{10}{|l|}{$U_{t, 3 m}^{\text {long }}$} \\
\hline IP & 16.43 & 1.89 & 10.07 & 7.90 & 23.86 & 1.44 & 12.30 & 1.75 & 5.18 \\
\hline CPI inflation & 5.88 & 1.74 & 5.85 & 3.59 & 4.60 & 1.43 & 6.08 & 2.21 & 6.72 \\
\hline PPI & 8.32 & 2.52 & 3.81 & 2.88 & 3.54 & 2.40 & 3.03 & 2.07 & 1.97 \\
\hline Retail & 4.48 & 1.71 & 9.42 & 6.87 & 1.96 & 1.98 & 11.39 & 2.50 & 2.32 \\
\hline Unemployment & 22.92 & 1.57 & 2.33 & 8.19 & 2.34 & 1.40 & 23.66 & 1.41 & 3.84 \\
\hline
\end{tabular}

Notes: Posterior median of FEVD from the individual VARs with following order of variables:

$y_{t}=\left(U_{t}^{x}(h), i p_{t}, \pi_{t}, \pi_{t}^{d}, r t_{t}, u r_{t}\right)$. Results above from two VARs, where interest rate uncertainty is either on the short or the long yield, $U_{t, 3 m}^{\text {short }}$ and $U_{t, 3 m}^{l o n g}$, respectively. We report the maximum fraction of variance (from the posterior median) in each variable.

Emphasizing cross-country results, short-yield uncertainty explains between 42 to 59 percent of the variation in industrial production in Germany, France and Spain. This shock is less important in Japan and Italy, with FEVD reaching up to 6 percent. Regarding unemployment, the contribution is substantial for the US (up to 40 percent) and Spain (up to 43 percent). In Canada both short- and longyield uncertainty have considerable effects on unemployment (up to 24 percent). With respect to prices, the median FEVD ranges from 1 to 32 percent, with the extremes pertaining to Italy and Spain, respectively. Notably, this shock has a large contribution to the variation in prices in European countries. For inflation targeting countries, the contribution of this shock is higher for consumer prices (up to 30 percent) than for producer prices (up to 7.8 percent).

\subsubsection{Cross-country differential effects of interest rate uncertainty shocks}

Our analysis shows that there is substantial heterogeneity across countries with respect to the size and the persistence of macro responses to interest rate uncertainty shocks. Below we discuss how these differential effects relate with certain 
characteristics of the economies under investigation. To this aim, in line with the literature that studies asymmetries in the transmission of monetary policy across regions, we look at two dimensions that are found to be important in explaining these asymmetries: the mix of interest-sensitive industries and labor market rigidities (see Carlino and Defina, 1998; Georgiadis, 2014, 2015, for the US and the euro area, respectively). For example, under the interest rate channel hypothesis of monetary policy transmission, countries that have a higher share of interest-sensitive industries are expected to experience a higher effect of monetary policy. Furthermore, as DSGE models in the spirit of Leduc and Liu (2016) show, labor market frictions are important for the propagation of uncertainty shocks.

Figure 7: Short-interest rate uncertainty effects and value added by activity
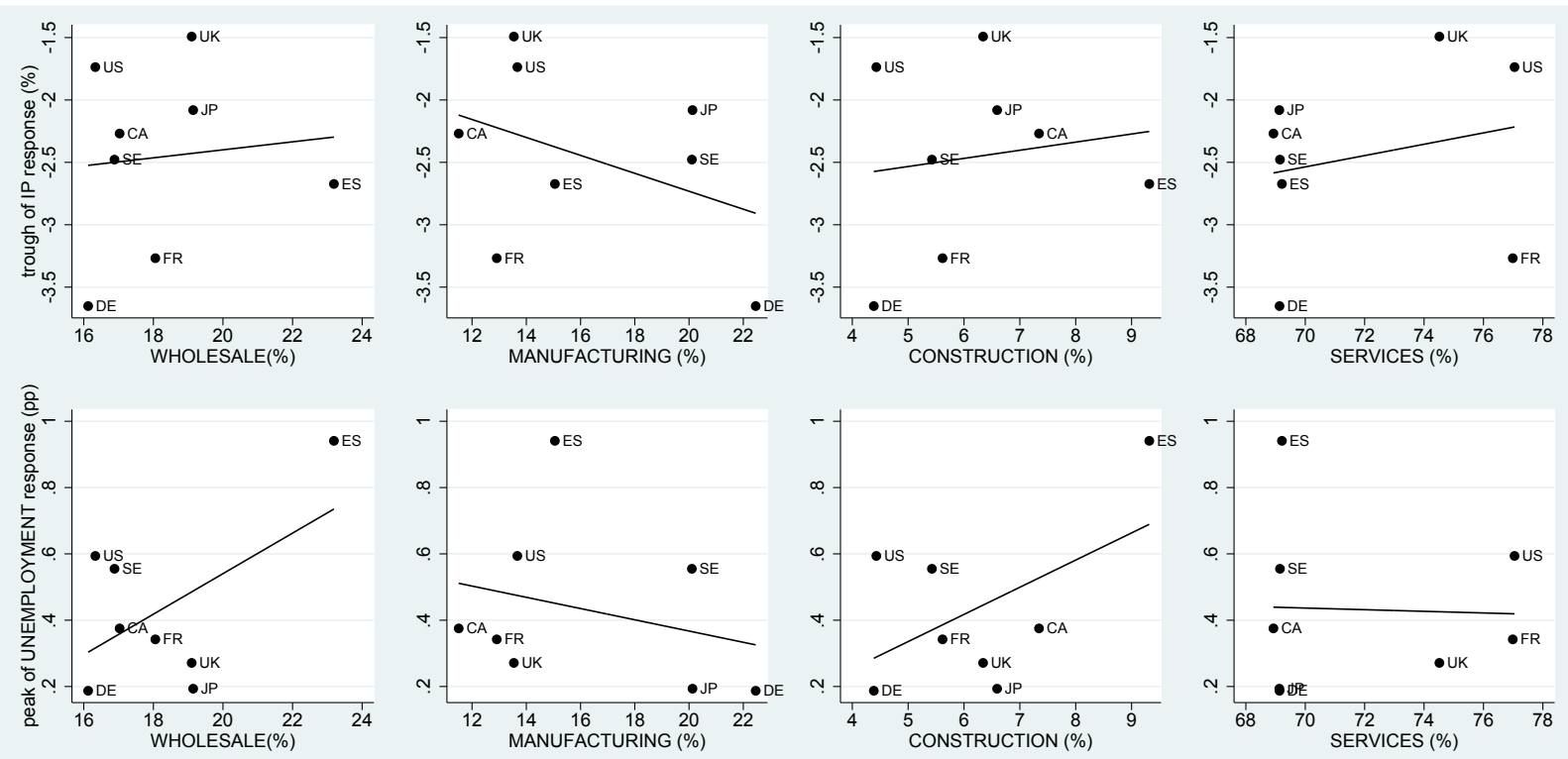

Notes: Trough (peak) response of industrial production (unemployment rate) to $U_{t}^{s h o r t}(h)$ represent the trough (peak) of the median response estimated from country-BVARs. Value added by activity breaks down the total value added by sector, namely agriculture, industry, utilities, and other service activities. The shares of each sector are calculated by dividing the value added in each sector by total value added (Source: OECD and World Bank). Wholesale denotes wholesale, retail trade, repairs; hotels, restaurants; transport. All the shares represent averages of the sample period into consideration.

To investigate these links, we look at how the trough (peak) responses of industrial production (unemployment rate) to interest rate uncertainty relate with cross-country differences with respect to the industry mix and labor market rigidities. Given the few data points, the evidence below is only suggestive. Figure 7 displays the link between the trough responses of industrial production and the share of value added accounted for by the wholesale, manufacturing, construction and services sector. ${ }^{17}$ These data patterns suggest that countries with a larger share in manufacturing, like Germany and Sweden, display stronger declines in industrial production in response to short-yield uncertainty $\left(R^{2}=0.16\right)$. This pattern is also observed for the long-yield uncertainty (see Figure 11 in the Appendix A). With re-

\footnotetext{
${ }^{17}$ Given the non-significant effects of uncertainty, we exclude Italy from this analysis.
} 
spect to unemployment, the effects of interest rate uncertainty are larger in countries with a higher share in wholesale and construction sectors, like the case of Spain.

In regard to labor market rigidities, we look at the OECD's indicators of employment protection and the labor regulation index by Botero et al. (2004). The first is a synthetic indicator of the strictness of regulation on dismissals and the use of temporary contracts. Further, the labor regulation index by Botero et al. (2004) deals with employment laws, collective relations laws, and social security laws. A caveat is that this index is measured as of data in 1997/1999. The relationship between the trough (peak) response of industrial production (unemployment) to the short-yield uncertainty and measures of labor market rigidities are displayed in Figure 8.

Figure 8: Short-interest rate uncertainty effects and labor market rigidity

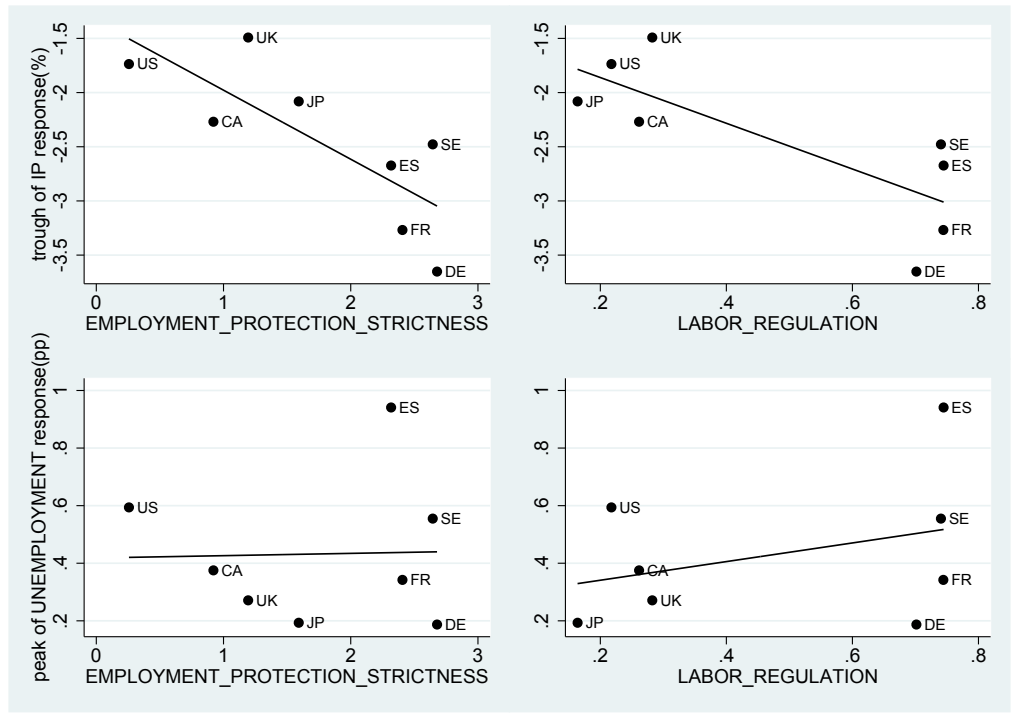

Notes: Trough (peak) response of industrial production (unemployment rate) to $U_{t}^{\text {short }}(h)$ represent the trough (peak) of the median response estimated from country-BVARs. Indicators of employment protection represent averages of the sample period into consideration. Source: OECD and Botero et al. (2004).

We observe that countries with more rigid labor indicators tend to have stronger declines in industrial production (for both lines in Figure 8, $R^{2}=0.6$ ). Labor market rigidities impose higher costs for firms in hiring and firing therefore when coupled with uncertainty the results on the economy are more adverse. Similar patterns are found for the long-yield uncertainty (see Figure 12 in the Appendix A). In addition, higher labor regulation is associated with larger effects of interest rate uncertainty on the unemployment rate. The suggestive evidence on the link between employment protection regulations and unemployment responses is less clear. The purpose of this regulation is to protect existing jobs, therefore it reduces inflows into unemployment. At the same time, this regulation reduces chances of unemployed workers to get hired, thus contributing to long-term unemployment. 


\section{Conclusion}

In this paper we ask whether uncertainty about interest rates is important for economic activity. To answer this question we first build measures of subjective interest rate uncertainty based on forecasts of short- and long-term interest rates, accounting for both disagreement among forecasters and the perceived variability of future aggregate shocks. Then, using a VAR approach we identify the effect of subjective interest rate uncertainty on the economy. The timing of surveys is exploited at the identification stage, for credible restrictions in line with the data. Moreover, our investigation has a multi-country dimension. We provide measures of interest rate uncertainty for a number of countries, including the US, Japan, the UK, Canada, Sweden, Germany, France, Italy, and Spain. Under this setup, we study if there is heterogeneity on the effects of uncertainty across different economies, and if so, why?

We show that shocks to interest rate uncertainty have large and persistent negative effects on most of our countries under investigation. These shocks induce a decline in industrial production and unemployment. Furthermore, they are deflationary. With respect to the maturity of the yield, we find that short-yield uncertainty explains a larger fraction of our selected macroeconomic variables. When looking at disaggregated components of uncertainty, we find that both disagreement and the perceived variability of shocks push the economy in the same direction. In an attempt to look at what could explain the heterogeneity of our results across countries, we observe that the effects of interest rate uncertainty are higher in countries with a larger share of interest-rate sensitive sectors and more labor market rigidities.

Our results show that subjective uncertainty about the short yield is important for macroeconomic fluctuations and suggest an important role of central banks in achieving a stable environment. As long as interest rate uncertainty is tied to uncertainty about monetary policy, operational frameworks and strategies devised by central banks can inhibit them. Should fundamentals be the source of interest rate uncertainty, central banks can actively take part in moderating it. In fact, since the Great Recession, major central banks use communicating policies (i.e., forward guidance), allowing them to reduce the uncertainty around the future path of short-term interest rates.

Despite preliminary evidence on potential drivers of cross-country differential effects of interest rate uncertainty, this study draws attention to the role of institutional frameworks in the propagation of uncertainty shocks. Furthermore, in this analysis all countries are studied individually and it would be interesting to provide a joint analysis where spillover effects are allowed and investigated. We plan to analyze these issues in future research. 


\section{References}

Bachmann R, Elstner S, Sims ER. 2013. Uncertainty and economic activity: Evidence from business survey data. American Economic Journal: Macroeconomics 5: 217-49.

Baker SR, Bloom N, Davis SJ. 2016. Measuring economic policy uncertainty. The Quarterly Journal of Economics.

Bernanke B. 1983. Irreversibility, uncertainty, and cyclical investment. The Quarterly Journal of Economics 98(1): 85-106.

Bianchi F, Melosi L. 2016. Constrained discretion and central bank transparency. The Review of Economics and Statistics .

Bloom N. 2009. The impact of uncertainty shocks. Econometrica 77: 623-685.

Boero G, Smith J, Wallis KF. 2008. Uncertainty and disagreement in economic prediction : the Bank of England survey of external forecasters. Economic Journal 118: 1107-1127.

Botero JC, Djankov S, Porta RL, de Silanes FL, Shleifer A. 2004. The regulation of labor. The Quarterly Journal of Economics 119: 1339-1382.

Caggiano G, Castelnuovo E, Groshenny N. 2014. Uncertainty shocks and unemployment dynamics in U.S. recessions. Journal of Monetary Economics 67: 78-92.

Carlino G, Defina R. 1998. The differential regional effects of monetary policy. The Review of Economics and Statistics 80: 572-587.

Christiano LJ, Eichenbaum M, Evans CL. 1999. Chapter 2 monetary policy shocks: What have we learned and to what end? volume 1, Part A of Handbook of Macroeconomics. Elsevier, $65-148$.

Creal DD, Wu JC. 2016. Monetary Policy Uncertainty and Economic Fluctuations. International Economic Review .

D'Amico S, Orphanides A. 2014. Inflation uncertainty and disagreement in bond risk premia. Technical report.

Diether KB, Malloy CJ, Scherbina A. 2002. Differences of opinion and the cross section of stock returns. Journal of Finance 57: 2113-2141.

Dixit A, Pindyck RS. 1994. In Investment under Uncertainty. Princeton University Press, Princeton, New Jersey.

Ehrmann M, Eijffinger S, Fratzscher M. 2012. The role of central bank transparency for guiding private sector forecasts. Scandinavian Journal of Economics 114: 1018-1052.

Eusepi S, Preston B. 2010. Central bank communication and expectations stabilization. American Economic Journal: Macroeconomics 2: 235-71.

Fernandez-Villaverde J, Guerron-Quintana P, Kuester K, Rubio-Ramirez J. 2015. Fiscal volatility shocks and economic activity. American Economic Review 105: 3352-84.

Georgiadis G. 2014. Towards an explanation of cross-country asymmetries in monetary transmission. Journal of Macroeconomics 39: 66-84. 
Georgiadis G. 2015. Examining asymmetries in the transmission of monetary policy in the euro area: Evidence from a mixed cross-section global VAR model. European Economic Review 75: 195-215.

Giordani P, Soderlind P. 2003. Inflation forecast uncertainty. European Economic Review 47: 1037-1059.

Harvey A, Ruiz E, Shephard N. 1994. Multivariate Stochastic Variance Models. Review of Economic Studies 61: 247-264.

Istrefi K, Piloiu A. 2014. Economic policy uncertainty and inflation expectations. Working papers 511, Banque de France.

Jurado K, Ludvigson SC, Ng S. 2015. Measuring uncertainty. American Economic Review 105: $1177-1216$.

Kilian L, Vega C. 2011. Do energy prices respond to U.S. macroeconomic news? A test of the hypothesis of predetermined energy prices. The Review of Economics and Statistics 93: $660-671$.

Lahiri K, Sheng X. 2010. Measuring forecast uncertainty by disagreement: The missing link. Journal of Applied Econometrics 25: 514-538.

Leduc S, Liu Z. 2016. Uncertainty shocks are aggregate demand shocks. Journal of Monetary Economics 82: 20-35.

Leduc S, Sill K. 2013. Expectations and economic fluctuations: an analysis using survey data. The Review of Economics and Statistics 95: 1352-1367.

Ludvigson SC, Ma S, Ng S. 2015. Uncertainty and business cycles exogenous impulse or endogenous response? NBER Working Paper 21803, NBER Working Paper.

Mankiw NG, Reis R, Wolfers J. 2004. Disagreement about inflation expectations. In NBER Macroeconomics Annual 2003, Volume 18, NBER Chapters. National Bureau of Economic Research, Inc, 209-270.

Mumtaz H, Zanetti F. 2013. The impact of the volatility of monetary policy shocks. Journal of Money, Credit and Banking 45(4): 535-558.

Orphanides A. 2000. Errors in the measurement of the output gap and the design of monetary policy. Journal of Economics and Business 52: 117 - 141.

Ozturk EO, Sheng XS. 2016. Measuring global and country-specific uncertainty shocks. Technical report. Mimeo.

Rich R, Tracy J. 2010. The relationships among expected inflation, disagreement, and uncertainty: Evidence from matched point and density forecasts. The Review of Economics and Statistics 92: 200-207.

Taylor SJ. 1994. Modeling stochastic volatility: A review and comparative study. Mathematical Finance 4: 183-204.

Uhlig H. 2005. What are the effects of monetary policy on output? results from an agnostic identification procedure. Journal of Monetary Economics $\mathbf{5 2}$. 
Zarnowitz V, Lambros LA. 1987. Consensus and uncertainty in economic prediction. Journal of Political Economy 95: 591-621. 


\section{A Subjective long-yield uncertainty}

Figure 9: IRFs to long interest rate uncertainty shock across countries
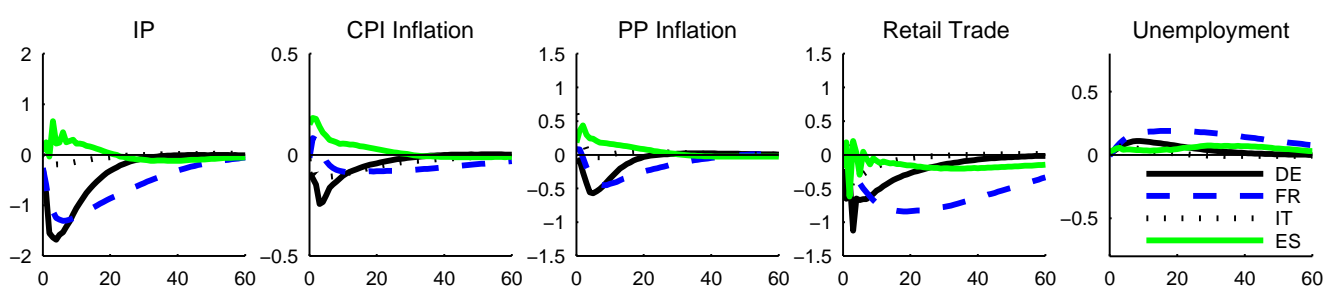

Euro Area (DE, FR, IT, ES)
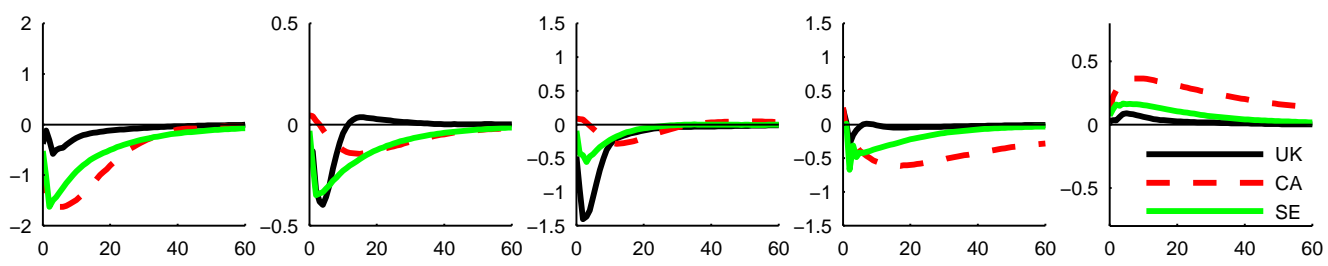

Inflation Targeting (UK, CA, SE)
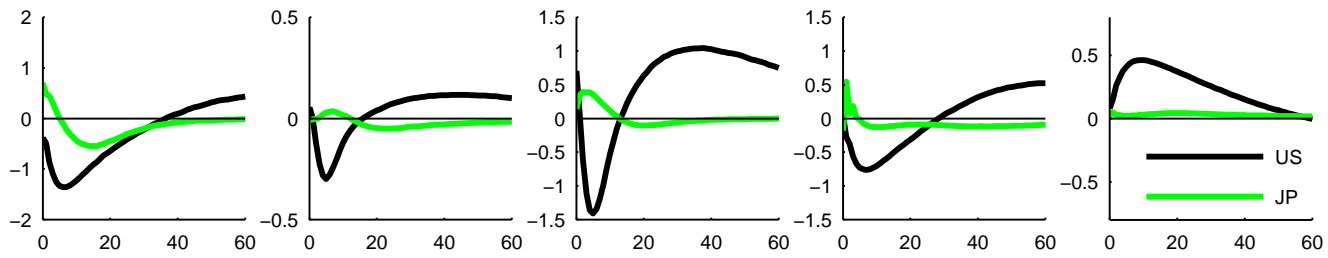

Others (US, JP)

Notes: IRFs to interest rate uncertainty for the 10 Year bond, 3-months ahead. The solid line in black denotes median impulse response from the estimated BVARs with $y_{t}=\left(U_{t}^{x}(h), i p_{t}, \pi_{t}, \pi_{t}^{d}, r t_{t}, u r_{t}\right)$. VARs include an exogenous variable, oil prices, a constant and a time trend. The response of IP (Industrial Production) and Retail (retail trade) are in percent and for prices and unemployment rate in percentage points. Horizontal axis is in months. 
Figure 10: IRFs to components of long interest rate uncertainty shocks

Disagreement
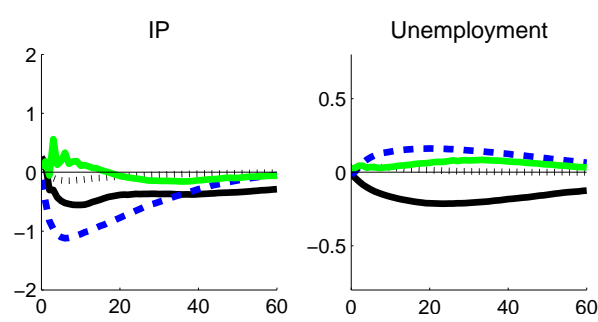

Common Uncertainty
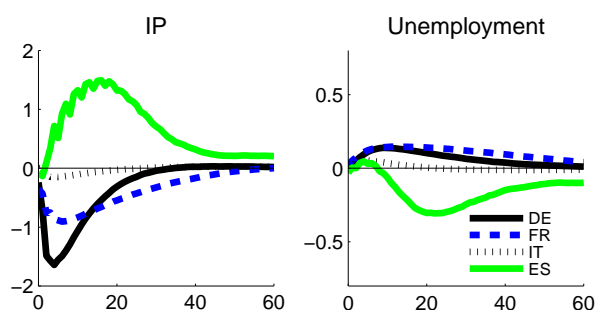

Euro Area (DE, FR, IT, ES)
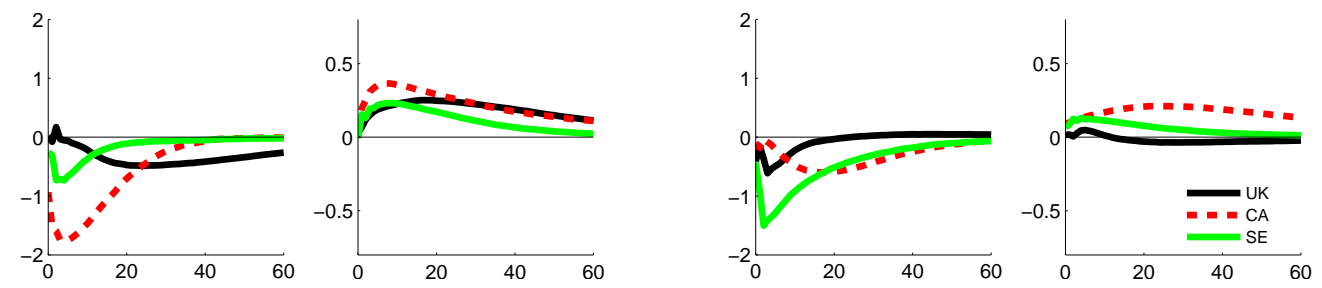

Inflation Targeting (UK, CA, SE)
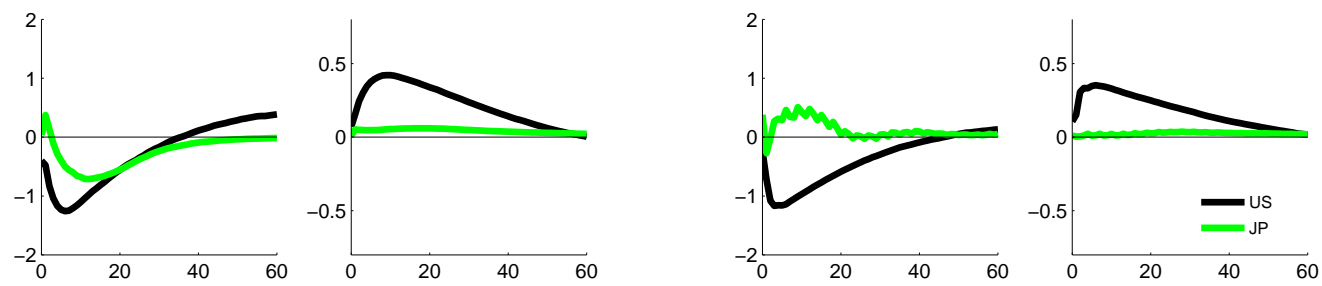

Others (US, JP)

Notes: IRFs in the first column, Disagreement, are estimated from country-specific VARs with $y_{t}=$ $\left.\left(D_{t}^{x}(h), i p_{t}, \pi_{t}, \pi_{t}^{d}, r t_{t}, u r_{t}\right)\right)$ and those in the second column, Common Uncertainty, are estimated from countryspecific VARs with $y_{t}=\left(V_{t}^{x}(h), i p_{t}, \pi_{t}, \pi_{t}^{d}, r t_{t}, u r_{t}\right)$. The solid line in black denotes median impulse response from the estimated BVARs with $y_{t}=\left(U_{t}^{x}(h), i p_{t}, \pi_{t}, \pi_{t}^{d}, r t_{t}, u r_{t}\right)$. VARs include an exogenous variable, oil prices, a constant and a time trend. The response of IP (Industrial Production) and Retail (retail trade) are in percent and for prices and unemployment rate in percentage points. Horizontal axis is in months. 
Figure 11: Long-interest rate uncertainty effects and value added by activity
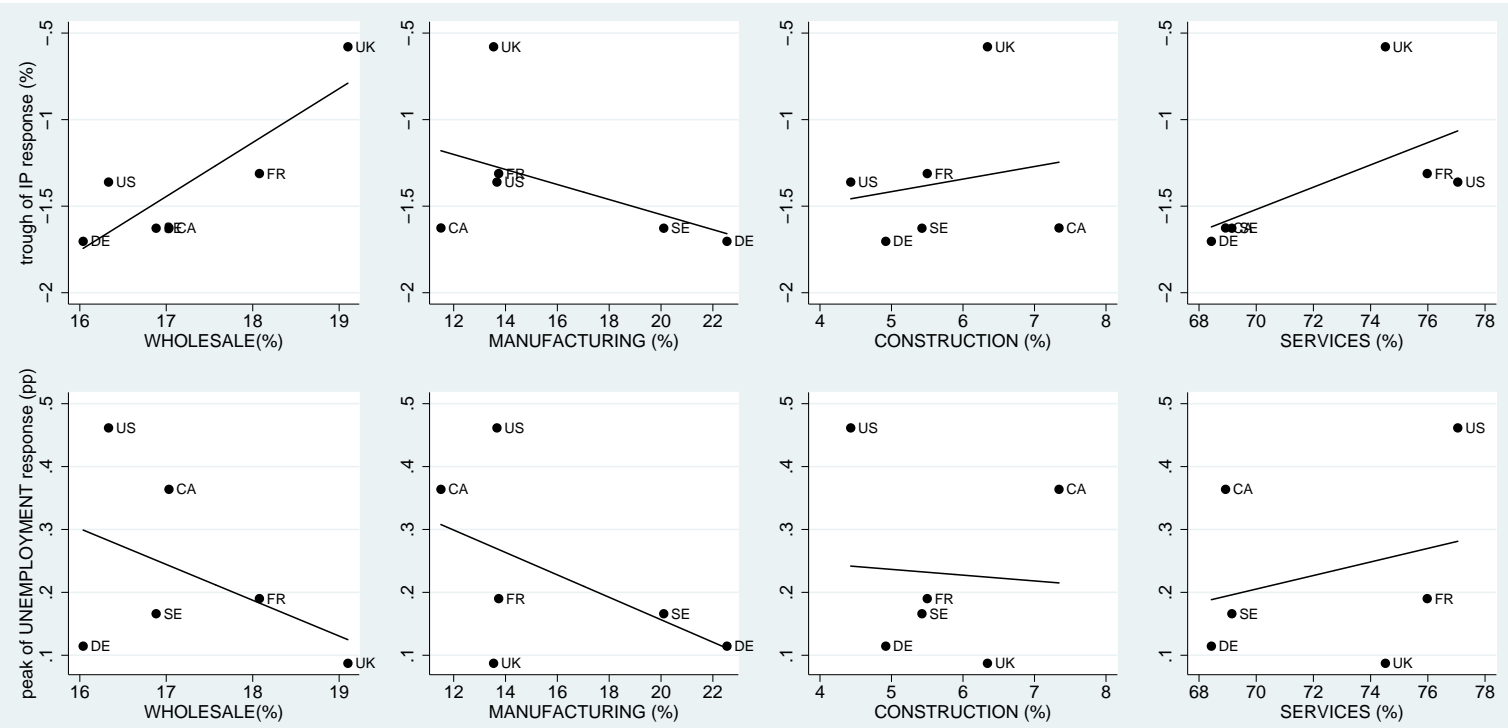

Notes: Trough (peak) response of industrial production (unemployment rate) to $U_{t}^{\text {long }}(h)$ represent the trough (peak) of the median response estimated from country-BVARs. Value added by activity breaks down the total value added by sector, namely agriculture, industry, utilities, and other service activities. The shares of each sector are calculated by dividing the value added in each sector by total value added (Source: OECD and World Bank). Wholesale denotes wholesale, retail trade, repairs; hotels, restaurants; transport. All the shares represent averages of the sample period into consideration. Given the non-significant effects of uncertainty, we exclude Italy, Spain and Japan from this analysis.

Figure 12: Long-interest rate uncertainty effects and labor market rigidity

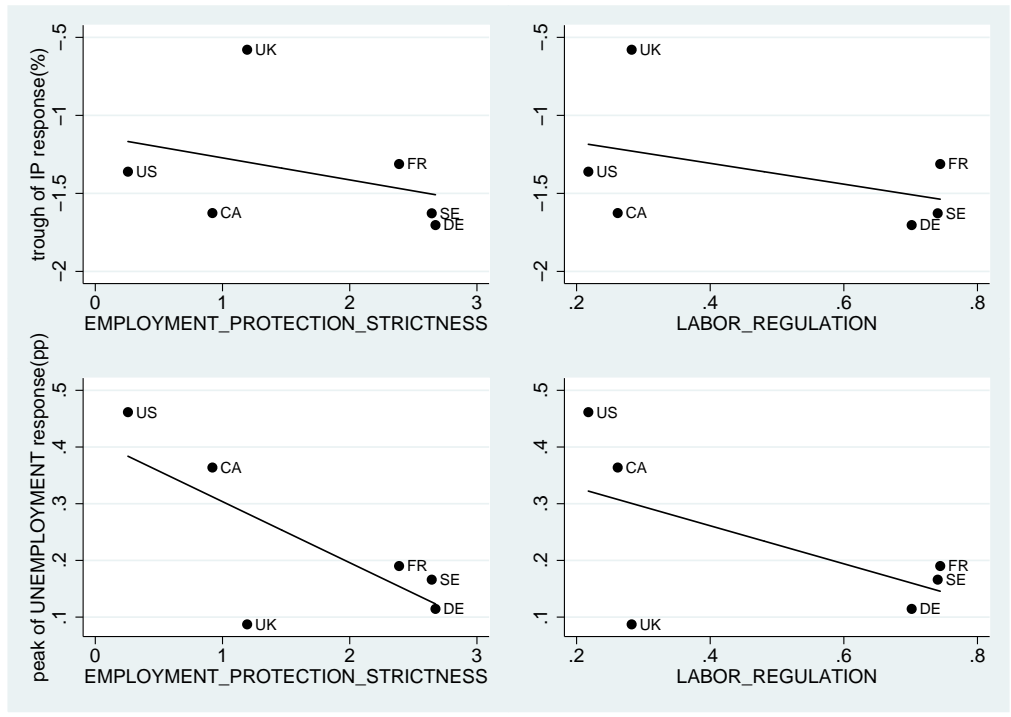

Notes: Trough (peak) response of industrial production (unemployment rate) to $U_{t}^{\text {long }}(h)$ represent the trough (peak) of the median response estimated from country-BVARs. Indicators of employment protection represent averages of the sample period into consideration. Source: OECD and Botero et al. (2004). Given the non-significant effects of uncertainty, we exclude Italy, Spain and Japan from this analysis. 
Figure 13: IRFs to short interest rate uncertainty shock across countries (excluding ZLB period)
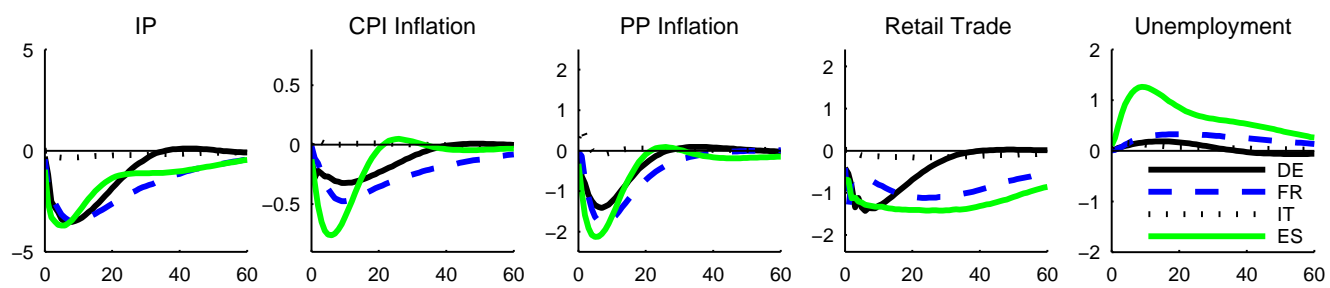

Euro Area (DE, FR, IT, ES)
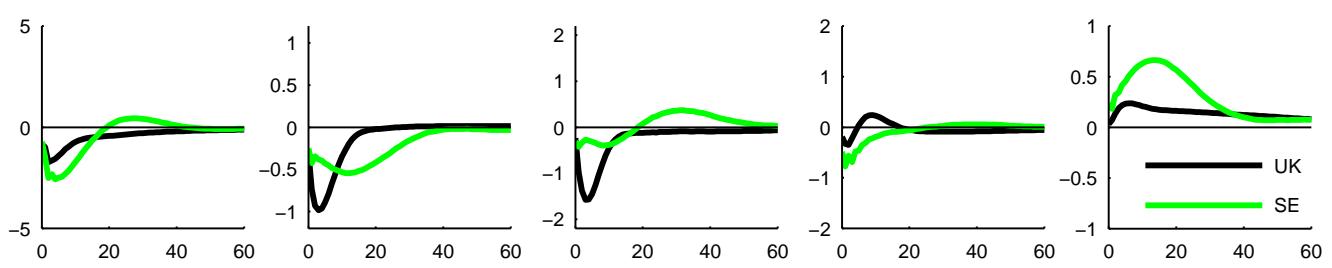

Inflation Targeting (UK, SE)
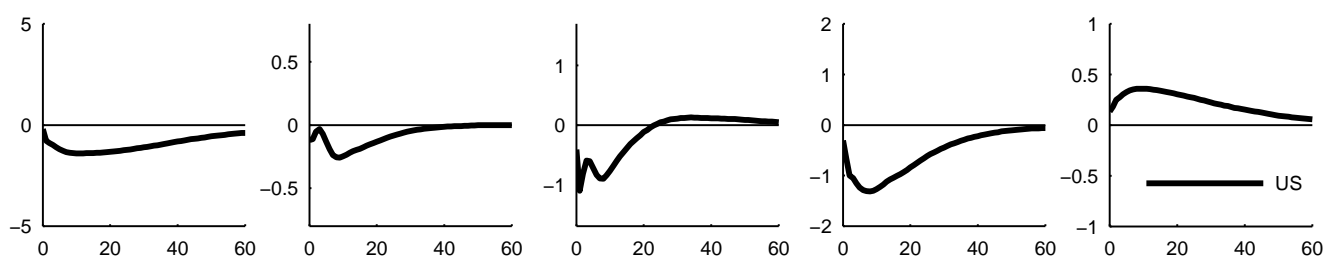

\section{Others (US)}

Notes: IRFs to interest rate uncertainty for the 3-month rate, 3-months ahead. The solid line in black denotes median impulse response from the estimated BVARs with $y_{t}=\left(U_{t}^{x}(h), i p_{t}, \pi_{t}, \pi_{t}^{d}, r t_{t}, u r_{t}\right)$. BVARs for the US, the UK, Sweden and the euro area are estimated with samples that exclude periods were policy rates reached levels close to zero. The cut-off dates for these countries are December 2008, March 2009, March 2009 and September 2014 , respectively. VARs include an exogenous variable, oil prices, a constant and a time trend. The response of IP (Industrial Production) and Retail (retail trade) are in percent and for prices and unemployment rate in percentage points. Horizontal axis is in months. 


\title{
Documents de Travail
}

602. O. de Bandt and M. Chahad, “A DGSE Model to Assess the Post-Crisis Regulation of Universal Banks” September 2016

603. C. Malgouyres, "The Impact of Chinese Import Competition on the Local Structure of Employment and Wages: Evidence from France" September 2016

604. G. Cette, J. Lopez and J. Mairesse, "Labour market regulations and capital labour substitution” October 2016

605. C. Hémet and C. Malgouyres, "Diversity and Employment Prospects: Neighbors Matter!” October 2016

606. M. Ben Salem and B. Castelletti-Font, "Which combination of fiscal and external imbalances to determine the longrun dynamics of sovereign bond yields?" November 2016

607. M. Joëts, V. Mignon and T. Razafindrabe, "Does the volatility of commodity prices reflect macroeconomic uncertainty?" November 2016

608. M. Bussière, G. Gaulier and W. Steingress, "Global Trade Flows: Revisiting the Exchange Rate Elasticities" November 2016

609. V.Coudert and J. Idier, “An Early Warning System for Macro-prudential Policy in France” November 2016

610. S. Guilloux-Nefussi, “Globalization, Market Structure and Inflation Dynamics” December 2016

611. S.Fries, J-S. Mésonnier, S. Mouabbi, and J-P. Renne, "National natural rates of interest and the single monetary policy in the Euro Area" December 2016

612. J. Blaum, C. Lelarge and M. Peters, “The Gains from Input Trade with Heterogeneous Importers” December 2016

613. A. Penalver, “Optimal Monitoring of Long-Term Loan Contracts” December 2016

614. M. Isoré and U. Szczerbowicz, “Disaster Risk and Preference Shifts in a New Keynesian Model” December 2016

615. L. Chauvet and L. Jacolin, "Financial Inclusion, Bank Concentration and Firm Performance” December 2016

616. P. A. Pintus, Y. Wen, and X. Xing, "The Inverted Leading Indicator Property and Redistribution Effect of the Interest Rate" December 2016

617. G. Cette, R. Lecat \& C. Ly-Marin, "Long-term growth and productivity projections in advanced countries" January 2017

618. V. Bignon and C. jobst, "Economic Crises and the Eligibility for the Lender of Last Resort: Evidence from 19th century France" January 2017

619. K. Istrefi, S. Mouabbi, "Subjective Interest Rate Uncertainty and the Macroeconomy: A Cross-country Analysis" January 2017

Pour accéder à la liste complète des Documents de Travail publiés par la Banque de France veuillez consulter le site : www.banque-france.fr

For a complete list of Working Papers published by the Banque de France, please visit the website: www.banque-france.fr

Pour tous commentaires ou demandes sur les Documents de Travail, contacter la bibliothèque de la Direction Générale des Études et des Relations Internationales à l'adresse suivante :

For any comment or enquiries on the Working Papers, contact the library of the Directorate General Economics and International Relations at the following address :

\author{
BANQUE DE FRANCE \\ 49- 1404 Labolog \\ 75049 Paris Cedex 01 \\ tél : 0033 (0)1 42977724 ou 0142926340 ou 4890 ou 6981 \\ email : 1404-ut@banque-france.fr
}

